\title{
Hypoxia-Ischemia and Hypothermia Independently and Interactively Affect Neuronal Pathology in Neonatal Piglets with Short-Term Recovery
}

\author{
Caitlin E. O'Brien ${ }^{a}$ Polan T. Santos ${ }^{a}$ Ewa Kulikowicz ${ }^{a}$ Michael Reyes $^{a}$ \\ Raymond C. Koehler ${ }^{\mathrm{a}}$ Lee J. Martin ${ }^{\mathrm{b}, \mathrm{c}}$ Jennifer K. Lee ${ }^{\mathrm{a}, \mathrm{c}}$ \\ a Department of Anesthesiology and Critical Care Medicine, Johns Hopkins University, Baltimore, MD, USA; \\ ${ }^{b}$ Department of Pathology, Johns Hopkins University, Baltimore, MD, USA; ' Pathobiology Graduate Training Program, \\ Johns Hopkins University, Baltimore, MD, USA
}

\section{Keywords}

Neonatal · Brain injury · Hypothermia therapy ·

Neurodegeneration · Neuroprotection .

Hypoxic-ischemic encephalopathy · Perinatal asphyxia

\begin{abstract}
Therapeutic hypothermia is the standard of clinical care for moderate neonatal hypoxic-ischemic encephalopathy. We investigated the independent and interactive effects of hypoxia-ischemia (HI) and temperature on neuronal survival and injury in basal ganglia and cerebral cortex in neonatal piglets. Male piglets were randomized to receive $\mathrm{HI}$ injury or sham procedure followed by $29 \mathrm{~h}$ of normothermia, sustained hypothermia induced at $2 \mathrm{~h}$, or hypothermia with rewarming during fentanyl-nitrous oxide anesthesia. Viable and injured neurons and apoptotic profiles were counted in the anterior putamen, posterior putamen, and motor cortex at $29 \mathrm{~h}$ after $\mathrm{HI}$ injury or sham procedure. Terminal deoxynucleotidyl transferase dUTP nick end labeling (TUNEL) identified genomic DNA fragmentation to confirm cell death.
\end{abstract}

Though hypothermia after $\mathrm{HI}$ preserved viable neurons in the anterior and posterior putamen, hypothermia prevented neuronal injury in only the anterior putamen. Hypothermia initiated $2 \mathrm{~h}$ after injury did not protect against apoptotic cell death in either the putamen or motor cortex, and rewarming from hypothermia was associated with increased apoptosis in the motor cortex. In non-HI shams, sustained hypothermia during anesthesia was associated with neuronal injury and corresponding viable neuron loss in the anterior putamen and motor cortex. TUNEL confirmed increased neurodegeneration in the putamen of hypothermic shams. Anesthetized, normothermic shams did not show abnormal neuronal cytopathology in the putamen or motor cortex, thereby demonstrating minimal contribution of the anesthetic regimen to neuronal injury during normothermia. We conclude that the efficacy of hypothermic protection after $\mathrm{HI}$ is region specific and that hypothermia during anesthesia in the absence of $\mathrm{HI}$ may be associated with neuronal injury in the developing brain. Studies examining the potential interactions between hypothermia and anesthesia, as well as with longer durations of hypothermia, are needed.

(c) 2019 S. Karger AG, Base

\section{KARGER}

(c) 2019 S. Karger AG, Basel

E-Mail karger@karger.com

www.karger.com/dne
Caitlin E. O'Brien, MD, MPH

Department of Anesthesiology and Critical Care Medicine

Johns Hopkins University, 1800 Orleans Street, Bloomberg Tower, Suite 6349J

Baltimore, MD 21287 (USA)

E-Mail cobrie19@jhmi.edu 


\section{Introduction}

Therapeutic hypothermia has been the standard of clinical care for moderate-to-severe hypoxic-ischemic encephalopathy (HIE) in newborns for many years [1]. As clinicians become more comfortable with delivering hypothermia, considerations for its use have expanded to include babies with mild HIE [2-5]. The effects of temperature manipulation independent of hypoxia-ischemia (HI) on the developing brain must be studied as hypothermia is also considered for more diverse patient populations [6]. In some clinical situations, rewarming a neonate who inadvertently becomes hypothermic is essential for safety, including very low birthweight newborns [7] and in the perioperative period [8]. Therefore, we studied the independent and interactive effects of $\mathrm{HI}$ and temperature management on the developing brain.

We previously demonstrated that hypothermia preserved neuronal viability and reduced ischemic necrosis $[9,10]$ in a swine model of severe hypoxic-asphyxic brain injury manifesting in part as $80 \%$ loss of viable neurons in the putamen [11-14]. Here, we examined the independent and interactive effects of moderate $\mathrm{HI}$ and normothermia, sustained hypothermia, and hypothermia with rewarming in piglets that had lesser HI injury or that underwent sham procedure. We studied the neuropathology in the basal ganglia and cerebral cortex because these regions are known to be vulnerable both in our model [13, 15] and in human newborns with HIE [16]. Further, injury in these regions is associated with poor neurodevelopmental outcome $[17,18]$.

\section{Materials and Methods}

\section{Animal Preparation}

All procedures were approved by the Animal Care and Use Committee at Johns Hopkins University and complied with the United States Public Health Service Policy on the Humane Care and Use of Laboratory Animals and the Guide for the Care and Use of Laboratory Animals. Animal care ensured comfort and was in accordance with the National Institutes of Health Guidelines. To conserve animals, we analyzed the putamen and motor cortex from brains of piglets that we previously reported in studies of cerebral cortical and white matter injury and the unfolded protein response $[15,19,20]$. Twenty-four additional piglets were used for this study for western blots. Neonatal male piglets (1-2.5 kg, 2-3 days old) were randomized to sham procedure or $\mathrm{HI}$ injury followed by $29 \mathrm{~h}$ of normothermia, sustained hypothermia beginning at $2 \mathrm{~h}$ after injury or time equivalent, or hypothermia with rewarming. Age-matched, male, naïve piglets that did not receive surgical anesthesia, surgery, or HI were prepared as an additional control group.
We previously published our HI protocol $[15,19]$. Briefly, piglets were anesthetized via nose cone with $5 \%$ isoflurane in a 50/50\% nitrous oxide/oxygen mixture. After intubation, mechanical ventilation was initiated to maintain normocapnia and normoxia. The inhaled oxygen was decreased to $30 \%$ in a $70 / 30 \%$ nitrous oxide/ oxygen mixture, and the isoflurane was decreased to $2 \%$. The femoral vein and artery were cannulated for intravenous (IV) administration of $5 \%$ dextrose in normal saline $(4 \mathrm{~mL} / \mathrm{kg} / \mathrm{h})$ and fentan$\mathrm{yl}(20 \mu \mathrm{g}$ bolus followed by $20 \mu \mathrm{g} / \mathrm{kg} / \mathrm{h})$, as well as continuous arterial blood pressure monitoring. The isoflurane was discontinued after placement of the femoral cannulae, which takes an average of 10-15 min, and initiation of the fentanyl infusion. All piglets received IV vecuronium $(0.2 \mathrm{mg} / \mathrm{kg} / \mathrm{h})$ to prevent shivering during hypothermia and to provide a consistent anesthetic to all piglets. This anesthetic regimen does not affect white matter apoptosis [19], cortical apoptosis [15], the unfolded protein response [20], or brain proteasomes [21] in our model. Phenylephrine or dopamine was initiated when necessary to maintain the mean arterial blood pressure above $45 \mathrm{mmHg}$, which is the lower limit of autoregulation in neonatal swine [22].

\section{Systemic HI Injury}

We induced whole-body hypoxia by decreasing the inhaled oxygen to $10 \%$ for $45 \mathrm{~min}$ to achieve an oxyhemoglobin saturation of $30-35 \%$. The piglets then received room air for $5 \mathrm{~min}$. This brief reoxygenation period is required for cardiac resuscitation. We occluded the endotracheal tube for $7 \mathrm{~min}$ to produce asphyxia. Piglets were resuscitated with $50 \%$ oxygen, manual chest compressions, and IV epinephrine $(100 \mu \mathrm{g} / \mathrm{kg})$ [23]. Piglets that did not exhibit return of spontaneous circulation (ROSC) within 3 min were excluded. After resuscitation, the inhaled oxygen was decreased to $30 \%$ for the remainder of the experiment. Sodium bicarbonate and calcium chloride were administered to correct metabolic acidosis and hypocalcemia, as necessary. Sham-operated piglets received the same femoral cannulae, duration of anesthesia, and $30 \%$ inhaled oxygen without $\mathrm{HI}$ injury.

\section{Temperature Management}

In addition to randomization to $\mathrm{HI}$ or sham procedure, piglets were also randomized to one of three temperature treatments: (1) normothermia (rectal temperature $38.0-39.5^{\circ} \mathrm{C}$, normothermic for swine), (2) hypothermia $\left(34.0^{\circ} \mathrm{C}\right)$ beginning $2 \mathrm{~h}$ after ROSC or time equivalent in sham groups, or (3) hypothermia with rewarming at $0.5^{\circ} \mathrm{C} / \mathrm{h}$, which is the clinical rewarming rate for HIE $[1,24]$. We used heating lamps and warming blankets to maintain normothermia or cooling blankets and ice packs to induce and maintain whole-body hypothermia. We delayed the induction of hypothermia by $2 \mathrm{~h}$ to mimic clinical delays. The $34.0^{\circ} \mathrm{C}$ target for hypothermia approximates the $4^{\circ} \mathrm{C}$ decrease achieved in clinical therapeutic hypothermia $\left(37^{\circ} \mathrm{C}\right.$ human normothermia with cooling to approximately $\left.33.5 \pm 0.5^{\circ} \mathrm{C}\right)[1,24,25]$. In our model, rectal temperature decreases to $34^{\circ} \mathrm{C}$ over $30 \mathrm{~min}$, and rectal and brain temperatures correlate within $0.2^{\circ} \mathrm{C}$ [10]. We initiated rewarming at $20 \mathrm{~h}$ after ROSC (after $18 \mathrm{~h}$ of hypothermia) by incrementally increasing the water temperature circulating through the blanket and by the use of heating lamps. Temperature management throughout the procedure was carefully monitored to avoid overcooling during hypothermia or hyperthermic overshoot during rewarming. The assigned temperature treatment was provided during $29 \mathrm{~h}$ of anesthesia, after which the animals were euthanized for
18

Dev Neurosci 2019;41:17-33

DOI: $10.1159 / 000496602$
O’Brien/Santos/Kulikowicz/Reyes/ Koehler/Martin/Lee 
histologic and biochemical measurements. This time point was selected because it correlates with observed maximal putamen injury $[13,14]$.

\section{Histology}

At $29 \mathrm{~h}$ after ROSC or time equivalent after sham procedure, piglets were deeply anesthetized with $50 \mathrm{mg} / \mathrm{kg}$ pentobarbital and transcardially perfused with cold phosphate-buffered saline followed by 4-6 L of ice-cold 4\% paraformaldehyde for brain fixation. The brain was stored overnight at $4{ }^{\circ} \mathrm{C}$ for in situ fixation. Afterwards, we gently removed the brain from the skull, avoiding any instrument and brain handling compression of tissue, cut it midsagittally, and immersed the right hemisphere in $4 \%$ paraformaldehyde for postfixation. The hemisphere was cut into $1 \mathrm{~cm}$ slabs that were embedded in paraffin and cut into $10-\mu \mathrm{m}$ coronal sections.

We analyzed anterior putamen at the striatal anatomic level and posterior putamen and motor cortex at the hippocampal anatomic level in one hemisphere with hematoxylin and eosin (H\&E) stain. Two investigators (C.E.O. and J.K.L.) counted viable neurons, injured neurons, and apoptotic profiles in putamen by light microscopy at $400 \times$ magnification in a total of 10-12 non-overlapping fields of $196 \mu \mathrm{m}^{2}$ per piglet. Cell counts were also conducted in cortical layers 2 and 3 of the entire motor gyrus at $400 \times$ magnification. These cortical layers were reliably identified $[14,26]$. Counter reliability was screened for accuracy by a third investigator (L.J.M.). In addition, 2 investigators (C.E.O. and J.K.L.) counted viable neurons and apoptotic profiles in the putamen in a random sample of piglets to test interrater reliability. Different microscope fields were counted within each pig for the interrater reliability assessments.

Viable neurons were defined as having a round or oval cell body (generally $8-10 \mu \mathrm{m}$ in diameter); open nucleus with visible chromatin strands within a diffuse nucleoplasmic matrix, often with a nucleolus; uninterrupted nuclear and cell membranes; normal thin rim of cytoplasm; and no apoptotic or ischemic morphology [15]. Apoptotic profiles were identified as cells with a few $(<4)$ crescent-shaped or spherical chromatin clumps in the nucleus, cytoplasmic condensation, and shrinkage into a round cell body profile with eosinophilic cytoplasm and intact cell membranes [27]. Most apoptotic profiles were at definite end-stage or near endstage, so the specific cell identity could not be determined. We did not count apoptotic profiles that were adjacent to or within 1 cell diameter of a blood vessel to exclude apoptotic white blood cells, pericytes, or endothelial cells.

We classified injured neurons based on their neuronal morphology as either (1) classical ischemic necrotic cytopathology or (2) eosinophilic cytoplasm with cytoplasmic vacuoles and darkened nucleoplasm, but without overt loss of the nucleoli or other signs of chromatin fragmentation and nuclear disintegration. Classical ischemic necrosis was defined by a shrunken, acutely angular cell body with homogeneous glassy, eosinophilic cytoplasm that contained microvacuoles without perinuclear pallor, and a hematoxylinstained pyknotic, angular nucleus with dark speckling of the nucleoplasmic matrix and no nucleolus [14, 15, 23, 28]. Representative images of viable, injured, and apoptotic profiles in the putamen are shown in Figure 1c-e. Figure $2 \mathrm{a}-\mathrm{c}$ shows examples of cortical pathology and neuronal classification.

We verified cell death using nuclear terminal deoxynucleotidyl transferase dUTP nick-end labeling (TUNEL) with the In-Situ Cell

Independent and Interactive Effects of $\mathrm{HIE}$ and Hypothermia in Neonatal Piglets
Death Detection Kit, POD (Roche Applied Science; Penzberg, Germany) as previously described [15]. Slides were developed with $3,3^{\prime}$-diaminobenzidine substrate and counterstained with cresyl violet. Negative controls were not exposed to terminal deoxynucleotidyl transferase, and positive controls were treated with DNase. One investigator (C.E.O.), who was masked to treatment group, counted TUNEL+ profiles. A representative TUNEL+ profile is shown in Figure 1f. We excluded TUNEL+ cells within or adjacent to blood vessels to avoid counting TUNEL+ blood-borne or endothelial cells.

\section{Immunoblotting}

These experiments were done to quantify various proteins involved in cell death, inflammation, and the unfolded protein response. All experiments were performed at $29 \mathrm{~h}$ after ROSC or time equivalent after sham procedure. Piglets were deeply anesthetized with $50 \mathrm{mg} / \mathrm{kg}$ pentobarbital and transcardially perfused with cold phosphate-buffered saline to harvest fresh brain tissue. Putamen was dissected from fresh brain slabs on dry ice. To conserve animals, we analyzed putamen tissue from piglets that we previously reported in studies of cortical [15] and white matter injury [19], as well as the unfolded protein response [20].

Brain samples were homogenized in ice-cold RIPA buffer (Cell Signaling Technology; Danvers, MA, USA), protease inhibitor cocktail (Invitrogen; Grand Island, NE, USA), and phosphatase inhibitor (Roche Applied Science) at a ratio of $1 \mathrm{~mL}$ per $0.1 \mathrm{~g}$ tissue. After the homogenates were centrifuged at $4{ }^{\circ} \mathrm{C}$, protein concentrations in the supernatant were measured with the Pierce BCA Protein Assay Kit (Thermo Fisher Scientific; Waltham, MA, USA). Samples were treated with loading buffer, boiled for $5 \mathrm{~min}$, separated by sodium dodecyl sulfate-polyacrylamide gel electrophoresis on $4-12 \%$ Tris-glycine gels, and transferred to nitrocellulose membranes. Each gel contained a putamen homogenate sample from each treatment group. After transfer, the membranes were stained with Ponceau S (Sigma Life Science; St. Louis, MO, USA) and imaged for quantification of protein loading. After being washed, the membranes were blocked in 5\% nonfat milk for $1 \mathrm{~h}$ at room temperature and then incubated overnight with primary antibody in $2 \%$ milk at $4{ }^{\circ} \mathrm{C}$ (online suppl. Table 1; see www.karger. com/doi/10.1159/000496602 for all online supplementary material). The membranes were incubated in anti-goat IgG (Jackson ImmunoResearch; West Grove, PA, USA), anti-mouse IgG (Jackson ImmunoResearch), or anti-rabbit IgG (GE Healthcare; Nottingham, UK) diluted 1:3,000 in 2\% milk for $2 \mathrm{~h}$ at room temperature. The membranes were imaged with enhanced chemiluminescence (Bio-Rad; Hercules, CA, USA) and iBright CL1000 Imaging System (Invitrogen). Immunoreactive band densities were analyzed with MyImageAnalysis version 2.0 (Thermo Fisher Scientific). The densities were normalized to Ponceau protein loading control for analysis. The sizes of the proteins of interest were determined using a molecular weight reference ladder (Precision Plus Protein Standards, Bio-Rad). The following immunoreactive bands were measured: (1) neuronal nuclei (NeuN, $46 \mathrm{kD}),(2)$ cleaved caspase-3 $(27 \mathrm{kD})$, (3) tumor necrosis factor alpha (TNFa, $35 \mathrm{kD})$, (4) mature Fas cell surface death receptor (Fas/CD95, $50 \mathrm{kD}$ ), (5) nitrotyrosine (all bands in each lane), (6) ionized calcium-binding adapter molecule 1 (Iba1, $17 \mathrm{kD}),(7)$ heat shock protein 70 (Hsp70, $72 \mathrm{kD}),(8)$ endoplasmic reticulum to nucleus signaling 1 (ERN1, $100 \mathrm{kD}),(9)$ protein kinase RNA-like endoplasmic reticulum kinase (PERK, 145 $\mathrm{kD}$ ), and phosphorylated ERN1 (pERN1, 90-110 kD). 

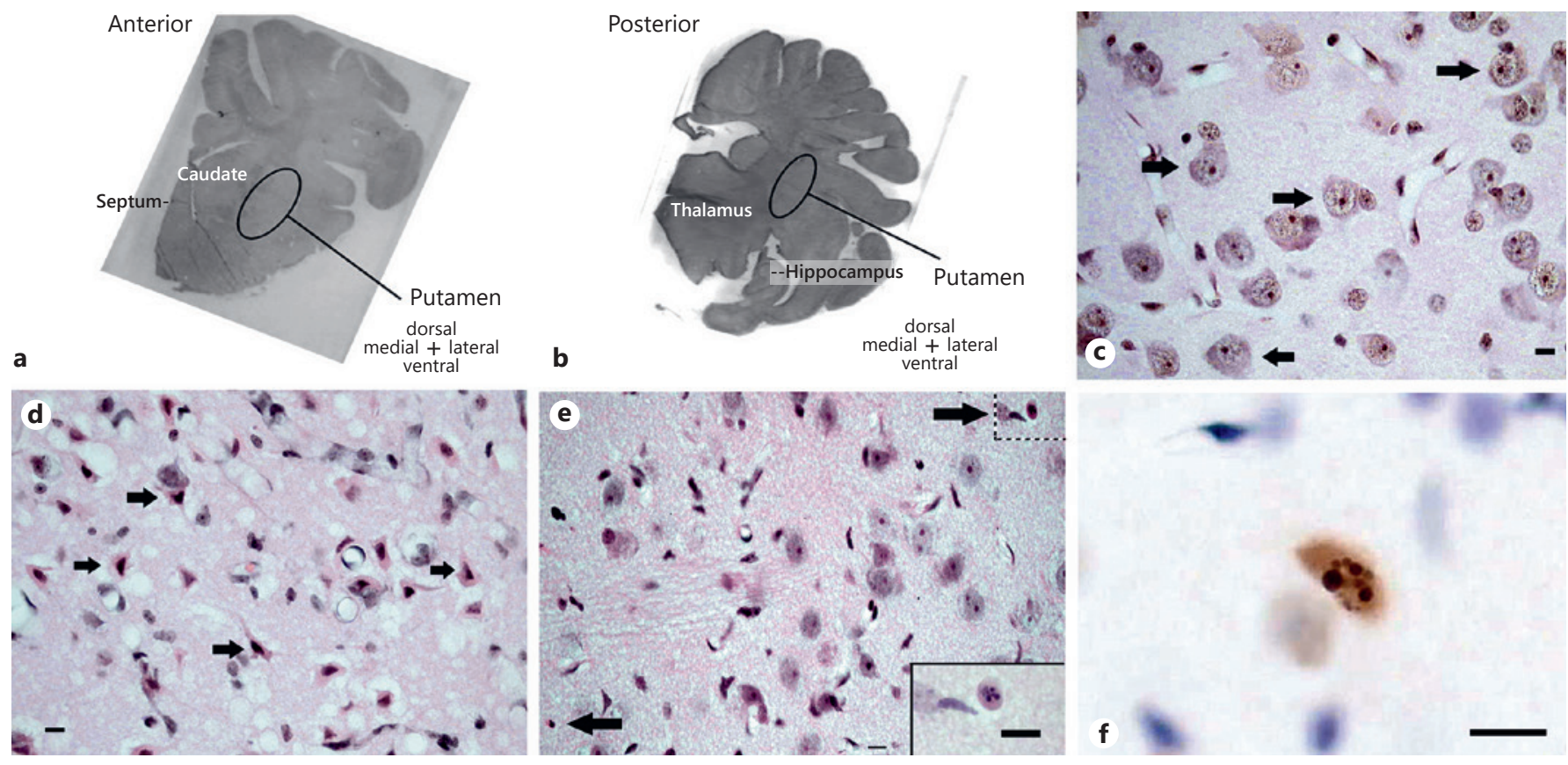

Fig. 1. Representative brain images from pigs that underwent sham surgery or HI injury. a, b Macrophotographs show the anterior and posterior levels of the putamen where viable, injured, and apoptotic profiles were counted. Photos are grayscale images of hematoxylin and eosin $(\mathrm{H} \& \mathrm{E})$-stained sections that were taken at $10 \times$ magnification. Brain section orientation is indicated at the lower right of each image. c H\&E-stained putamen in a sham-operated normothermic pig. Arrows denote morphologically viable neurons. Perineuronal, pericapillary, and parenchymal neuropil integrity appears excellent at this resolution. d H\&E-stained putamen in an HI normothermic pig. The arrows identify morphologically ischemic necrotic neurons, which were classified as injured for the analysis. Neuropil integrity is severely damaged as evidenced by the overt perineuronal, pericapillary, and parenchymal vacuoles. e H\&E-stained putamen in a shamoperated hypothermic pig. Arrows denote apoptotic profiles. The neuropil appears finely vacuolated with some pallor. The inset at lower right demonstrates an apoptotic profile at higher magnification (from upper right hatched box) for better visualization of spherical chromatin clumps in the nucleus. $f$ Representative TUNEL+ profile in a sham-operated hypothermic pig. The morphology of the DNA fragmentation and compartmentation seen as round aggregates is consistent with apoptosis. The cell size suggests that this apoptotic profile is a neuron. c-e were taken at $400 \times$ magnification. $\mathbf{f}$ was taken at $600 \times$ magnification with oil immersion. Scale bar is $10 \mu \mathrm{m}$.
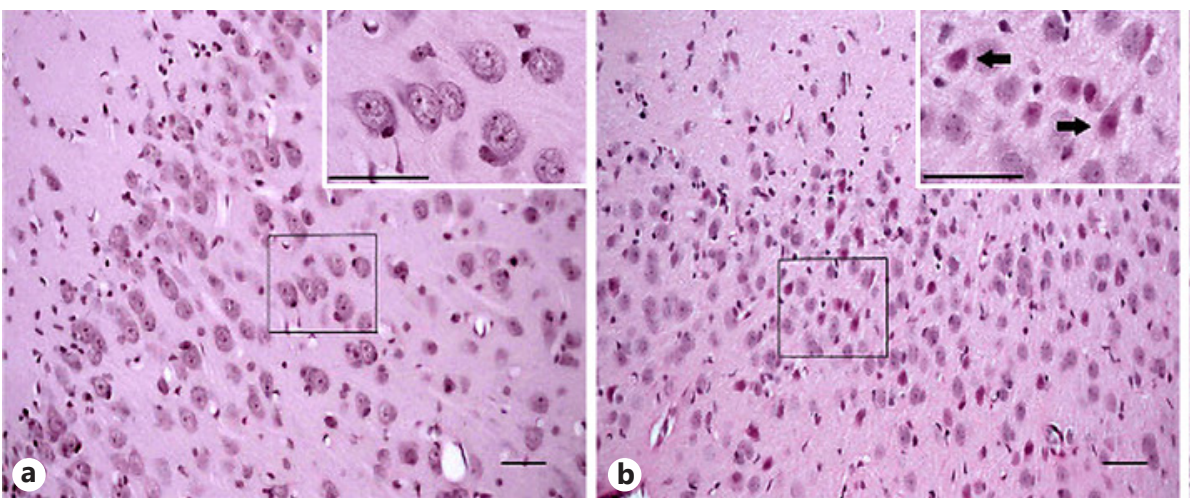

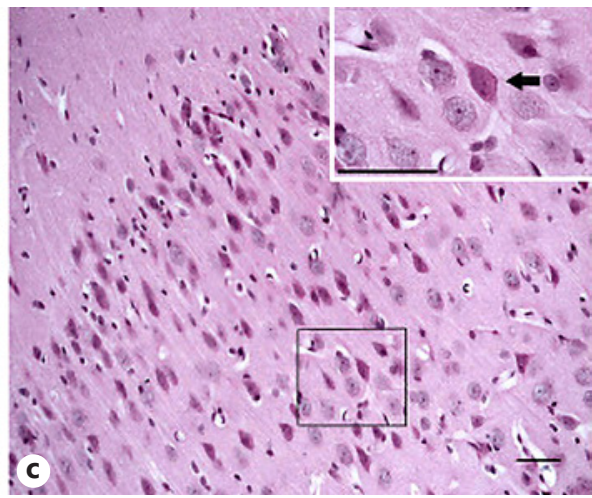

Fig. 2. Representative hematoxylin and eosin (H\&E)-stained sections of motor cortex in pigs that underwent sham surgery and normothermic recovery (a), sustained hypothermia (b), or hypothermia with rewarming $(\mathbf{c})$. Shown are low magnification panoramic and higher resolution (insets) views to appreciate the general anatomic locations and the cellular details. a In a sham normothermic piglet, neurons in layers 2 and 3 appear morphologically viable. b, c After hypothermia and hypothermia with rewarming, subsets of neurons are characterized by vacuolated, eosinophilic cytoplasm and nuclei that are dark and condensed but maintain nucleoli (arrows). The neuropil also shows spongiform changes. These neurons were classified as injured for the analysis. Photos taken at $200 \times$ magnification and insets taken at $600 \times$ magnification. Scale bar is $50 \mu \mathrm{m}$. 


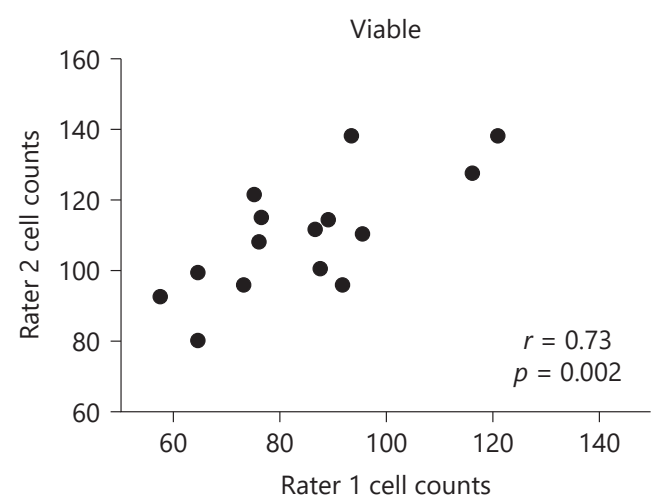

a

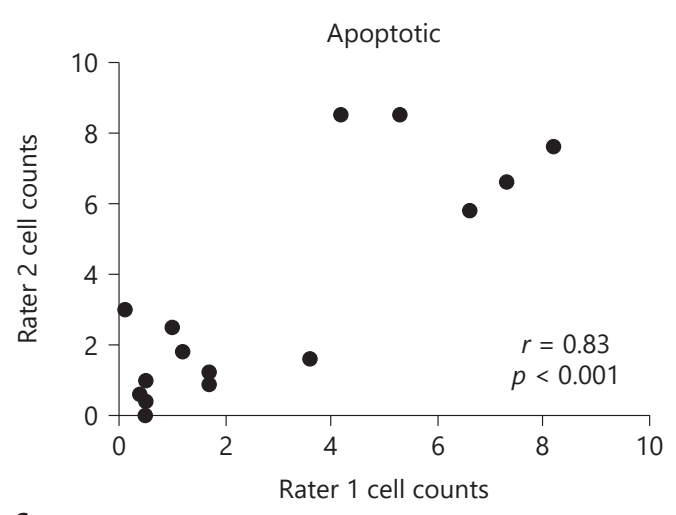

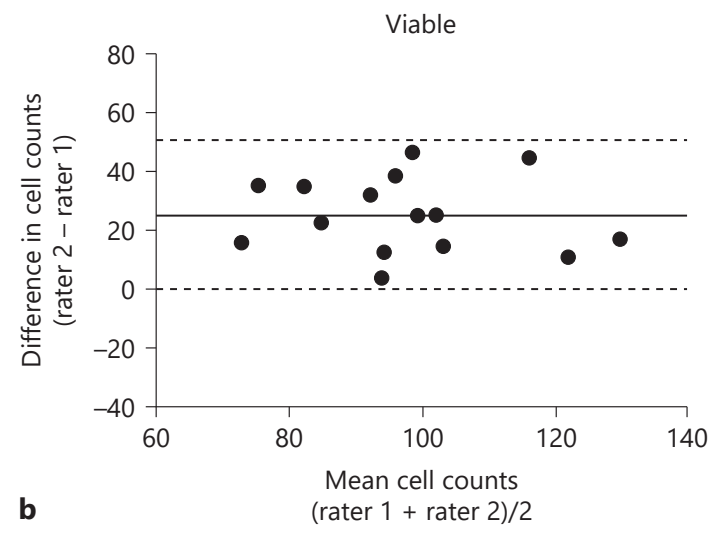

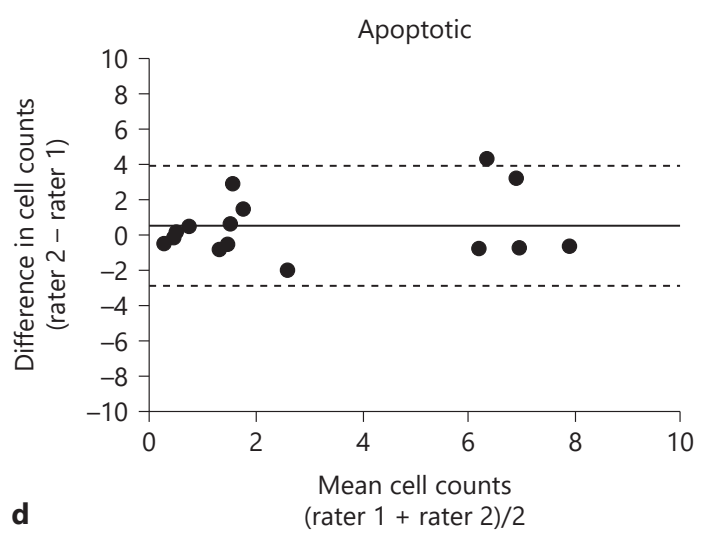

Fig. 3. Interrater reliability for counting viable neurons $(\mathbf{a}, \mathbf{b})$ and apoptotic profiles $(\mathbf{c}, \mathbf{d})$ on hematoxylin and eosin (H\&E)-stained sections in the putamen of 15 random piglets. Two investigators counted cells in different microscope fields of the same pig. Viable neuron counts $(\mathbf{a} ; r=0.73, p=0.002)$ and apoptotic profile counts

\section{Sample Size Calculations}

Because we had no a priori data for this model, we conducted a power estimate for detecting an effect of hypothermia after $\mathrm{HI}$ on viable neurons in the first third of animals. Viable neuron counts in the putamen of $3 \mathrm{HI}$ normothermic and $3 \mathrm{HI}$ hypothermic piglets had a difference in means of 17.4 and a within-group SD of 5.4. A sample size of 4 piglets/group would have a power of 0.90 at an alpha level of 0.05 .

\section{Statistical Analysis}

Analyses were conducted and graphs generated with SigmaPlot (version 11.2, Systat Software; Chicago, IL, USA) and GraphPad Prism (version 5.00, GraphPad Software; La Jolla, CA, USA). Data are graphed as box plots with interquartile ranges (IQR) and 5-95th percentile whiskers. Interrater reliability for viable neuron and apoptotic profile counts was analyzed with Pearson correlations and Bland-Altman plots. To examine for possible effects of the anesthetic, we compared cell counts between naïve perfused (c; $r=0.83, p<0.001)$ correlated between the investigators. BlandAltman plots for viable neurons (b) and apoptotic profiles (d). Bias is shown by the solid line. The $95 \%$ limits of agreement are shown by dotted lines. The apoptotic counts had near-zero bias, whereas bias was higher for viable neuron counts. and sham normothermic groups with Student's $t$ tests or MannWhitney $U$ tests for parametric and nonparametric data, respectively. We used Pearson correlation and Bland-Altman plots to test agreement between apoptotic profiles, as determined by $\mathrm{H} \& \mathrm{E}$ staining, and TUNEL+ profiles in paired (within pig) comparisons. Immunoblot densities were normalized to those of naïve pigs and then analyzed by Friedman tests with data blocked by gel. Cell counts between piglets that did or did not receive phenylephrine were compared by Mann-Whitney U tests.

To evaluate the effects of $\mathrm{HI}$ and temperature, we assessed the data distribution using the Shapiro-Wilk normality test. We transformed non-normal data by using a $\log (\mathrm{x}+1)$ function to generate normally distributed data. If this method did not generate a normal distribution, we used an $\arctan (\mathrm{x})$ function to achieve normality. We used 2-way analysis of variance to analyze the effects of HI, temperature, and their interactions on viable neuron, apoptotic profile, injured neuron, and TUNEL+ profile counts. Post hoc multiple comparisons were conducted with Holm-Sidak tests. 


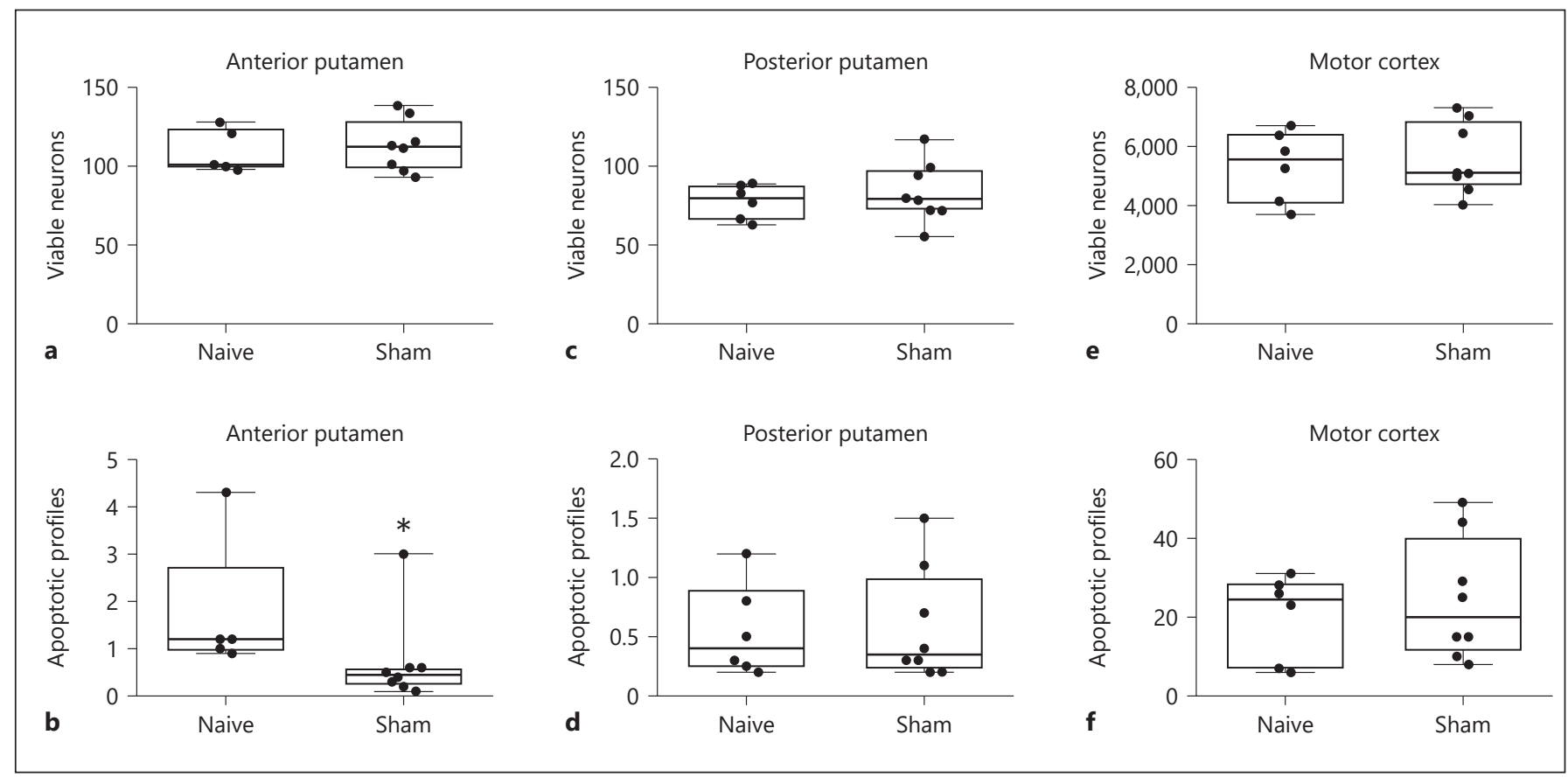

Fig. 4. Viable neuron and apoptotic profile counts in the anterior $(\mathbf{a}, \mathbf{b})$ and posterior $(\mathbf{c}, \mathbf{d})$ putamen and in motor cortex $(\mathbf{e}, \mathbf{f})$ of naive and sham pigs. Counts were made on hematoxylin and eosin (H\&E)-stained sections. The viable neuron counts were similar in naïve perfused and sham normothermic piglets ( $\mathbf{a}, p=0.693$ for anterior putamen; $\mathbf{c}, p=0.311$ for posterior putamen; $\mathbf{e}, p=0.852$

\section{Results}

\section{Treatment Groups and Sizes}

Anatomical level-matched sections from 6 naïve, 8 sham normothermia, 7 sham hypothermia, 7 sham rewarming, $6 \mathrm{HI}$ normothermia, $8 \mathrm{HI}$ hypothermia, and 8 HI rewarming piglets (50 total) were used for histologic assessment $[15,19]$. Motor cortex was analyzed in the same anatomical level as the posterior putamen. Several slides were not available for analysis and are described in Appendix 1. We analyzed western blots using tissue from 23 piglets that were part of prior studies $[15,19,20]$, and we analyzed putamen tissue from 24 new piglets.

\section{Physiology}

We reported blood gas and physiologic data, including the piglets' temperature, $\mathrm{pH}, \mathrm{PaCO}_{2}$, mean arterial blood pressure, hemoglobin, and sodium levels, in our prior studies $[15,19]$. We provide a summary of select parameters during the $\mathrm{HI}$ protocol here for the piglets from which we collected histologic data. During hypoxia the mean oxyhemoglobin saturation decreased to $26 \pm 8 \%$ in the normo- for motor cortex). Naïve piglets had more apoptosis than did sham piglets in the anterior putamen, with a difference in medians of 0.75 apoptotic profiles per microscope field ( $b, * p<0.05)$. Apoptotic profile counts did not differ in the posterior putamen $(\mathbf{d}, p=$ $1.00)$ or motor cortex (f, $p=0.651)$. Each circle represents 1 piglet. Box plots with IQRs and 5-95th percentile whiskers are shown.

thermic group, $30 \pm 9 \%$ in the hypothermic group, and 27 $\pm 6 \%$ in the rewarmed group. Asphyxia further decreased the oxyhemoglobin saturation to $3 \pm 1 \%$ in normothermic, $6 \pm 3 \%$ in hypothermic, and $5 \pm 4 \%$ in rewarmed piglets. Mean arterial pressure at end-asphyxia ranged from $42-52$ $\mathrm{mmHg}$. This blood pressure was higher than that in our previous severe $\mathrm{HI}$ model, in which mean arterial pressure was $18-25 \mathrm{mmHg}[10,29]$. Thus, piglets in the current study had less severe HI. Rectal temperatures were maintained at approximately $34^{\circ} \mathrm{C}$ during hypothermia and were achieved by $30 \mathrm{~min}$ into hypothermia. During rewarming, piglets were successfully rewarmed to $38-39^{\circ} \mathrm{C}$ without exceeding the goal temperature.

\section{Interrater Reliability}

In a random sample of 15 piglets, 2 investigators (C.E.O. and J.K.L.) counted 10-12 different microscopic fields in the putamen and there was significant correlation in viable neuron and apoptotic profile counts (Fig. 3a, c). Identification of apoptotic profiles had low bias between the investigators (Fig. 3d). Viable neuron counts had higher bias (Fig. 3b). 
Table 1. Cell profile counts in the putamen at the anterior and posterior levels

\begin{tabular}{|c|c|c|c|c|c|c|c|c|c|c|c|c|c|c|c|c|}
\hline \multirow{2}{*}{$\begin{array}{l}\text { Parameter/ } \\
\text { Group }\end{array}$} & \multicolumn{8}{|c|}{ Anterior level } & \multicolumn{8}{|c|}{ Posterior level } \\
\hline & $n$ & $\begin{array}{l}\text { H\&E viable } \\
\text { neurons }\end{array}$ & $n$ & $\begin{array}{l}\text { H\&E } \\
\text { injured } \\
\text { neurons }\end{array}$ & $n$ & $\begin{array}{l}\mathrm{H} \& \mathrm{E} \\
\text { apoptotic } \\
\text { profiles }\end{array}$ & $n$ & $\begin{array}{l}\text { TUNEL } \\
\text { profiles }\end{array}$ & $n$ & $\begin{array}{l}\text { H\&E viable } \\
\text { neurons }\end{array}$ & $n$ & $\begin{array}{l}\mathrm{H} \& \mathrm{E} \\
\text { injured } \\
\text { neurons }\end{array}$ & $n$ & $\begin{array}{l}\text { H\&E } \\
\text { apoptotic } \\
\text { profiles }\end{array}$ & $n$ & $\begin{array}{l}\text { TUNEL } \\
\text { profiles }\end{array}$ \\
\hline Naive & 5 & $\begin{array}{l}100.8 \\
(98.7-124.2)\end{array}$ & 5 & $\begin{array}{l}0 \\
(0-0.1)\end{array}$ & 5 & $\begin{array}{l}1.2 \\
(1.0-2.8)\end{array}$ & 6 & $\begin{array}{l}0.5 \\
(0.3-0.8)\end{array}$ & 6 & $\begin{array}{l}79.4 \\
(65.2-87.8)\end{array}$ & 6 & $\begin{array}{l}2.1 \\
(0.2-3.7)\end{array}$ & 6 & $\begin{array}{l}0.4 \\
(0.2-0.9)\end{array}$ & 6 & $\begin{array}{l}0.2 \\
(0.1-0.3)\end{array}$ \\
\hline $\begin{array}{l}\text { Sham } \\
\text { NormoT }\end{array}$ & 8 & $\begin{array}{l}112.2 \\
(98.1-129.0)\end{array}$ & 8 & $\begin{array}{l}0 \\
(0-0)\end{array}$ & 8 & $\begin{array}{l}0.5 \\
(0.2-0.6)\end{array}$ & 7 & $\begin{array}{l}0.8 \\
(0.5-1.9)\end{array}$ & 8 & $\begin{array}{l}84.3 \\
(75.9-97.8)\end{array}$ & 8 & $\begin{array}{l}0.6 \\
(0.2-2.6)\end{array}$ & 8 & $\begin{array}{l}0.4 \\
(0.2-1.0)\end{array}$ & 8 & $\begin{array}{l}0.2 \\
(0.1-0.3)\end{array}$ \\
\hline $\begin{array}{l}\text { Sham } \\
\text { HypoT }\end{array}$ & 7 & $\begin{array}{l}68.1 \\
(67.8-81.8)\end{array}$ & 7 & $\begin{array}{l}0.4 \\
(0.4-1.0)\end{array}$ & 7 & $\begin{array}{l}5.0 \\
(0.9-6.5)\end{array}$ & 6 & $\begin{array}{l}1.4 \\
(0.5-2.3)\end{array}$ & 6 & $\begin{array}{l}85.9 \\
(74.5-107.7)\end{array}$ & 6 & $\begin{array}{l}1.0 \\
(0.1-2.6)\end{array}$ & 6 & $\begin{array}{l}1.5 \\
(0.9-2.0)\end{array}$ & 7 & $\begin{array}{l}1.7 \\
(1.1-2.5)\end{array}$ \\
\hline $\begin{array}{l}\text { Sham } \\
\text { Rewarm }\end{array}$ & 7 & $\begin{array}{l}86.3 \\
(67.3-96.0)\end{array}$ & 7 & $\begin{array}{l}0.8 \\
(0.2-4.5)\end{array}$ & 7 & $\begin{array}{l}0.4 \\
(0.2-0.7)\end{array}$ & 7 & $\begin{array}{l}0.6 \\
(0.4-0.8)\end{array}$ & 7 & $\begin{array}{l}71.0 \\
(59.3-75.2)\end{array}$ & 7 & $\begin{array}{l}3.6 \\
(1.7-9.5)\end{array}$ & 7 & $\begin{array}{l}0.3 \\
(0.2-0.9)\end{array}$ & 6 & $\begin{array}{l}0.2 \\
(0.1-0.4)\end{array}$ \\
\hline $\begin{array}{l}\text { HI } \\
\text { NormoT }\end{array}$ & 6 & $\begin{array}{l}76.8 \\
(52.4-92.2)\end{array}$ & 6 & $\begin{array}{l}1.5 \\
(0.1-12.4)\end{array}$ & 6 & $\begin{array}{l}2.2 \\
(1.8-3.2)\end{array}$ & 5 & $\begin{array}{l}0.8 \\
(0.4-1.2)\end{array}$ & 6 & $\begin{array}{l}67.9 \\
(55.3-90.5)\end{array}$ & 6 & $\begin{array}{l}1.4 \\
(0.8-7.6)\end{array}$ & 6 & $\begin{array}{l}0.9 \\
(0.7-2.1)\end{array}$ & 4 & $\begin{array}{l}1.3 \\
(0.7-1.3)\end{array}$ \\
\hline $\begin{array}{l}\text { HI } \\
\text { HypoT }\end{array}$ & 7 & $\begin{array}{l}111.9 \\
(108.3-127.6)\end{array}$ & 7 & $\begin{array}{l}0 \\
(0-0)\end{array}$ & 7 & $\begin{array}{l}1.8 \\
(0.9-2.5)\end{array}$ & 8 & $\begin{array}{l}0.5 \\
(0.3-0.8)\end{array}$ & 8 & $\begin{array}{l}93.0 \\
(83.9-99.7)\end{array}$ & 8 & $\begin{array}{l}0.6 \\
(0.2-2.3)\end{array}$ & 8 & $\begin{array}{l}0.6 \\
(0.3-0.8)\end{array}$ & 8 & $\begin{array}{l}0.4 \\
(0.2-0.8)\end{array}$ \\
\hline $\begin{array}{l}\text { HI } \\
\text { Rewarm }\end{array}$ & 8 & $\begin{array}{l}104.7 \\
(96.6-119.9)\end{array}$ & 8 & $\begin{array}{l}0 \\
(0-1.4)\end{array}$ & 8 & $\begin{array}{l}4.2 \\
(0.8-8.2)\end{array}$ & 6 & $\begin{array}{l}0.7 \\
(0.5-1.0)\end{array}$ & 8 & $\begin{array}{l}102.0 \\
(88.9-108.3)\end{array}$ & 8 & $\begin{array}{l}1.0 \\
(0.3-4.2)\end{array}$ & 8 & $\begin{array}{l}0.8 \\
(0.6-1.0)\end{array}$ & 7 & $\begin{array}{l}0.3 \\
(0.2-0.6)\end{array}$ \\
\hline
\end{tabular}

Data are presented as median (IQR).

H\&E, hematoxylin and eosin; TUNEL, terminal deoxynucleotidyl transferase dUTP nick-end labeling; NormoT, sustained normothermia; HI, hypoxia-ischemia; HypoT, sustained hypothermia; Rewarm, hypothermia followed by rewarming.

\section{Effect of the Anesthetic}

The number of viable neurons in the anterior putamen was similar in naïve perfused $(n=5)$ and sham normothermic $(n=8)$ piglets $(p=0.693$; Fig. $4 a)$. Naïve piglets had more apoptosis in the anterior putamen than did sham piglets, with a difference in medians of 0.75 apoptotic profiles per microscope field $\left(196 \mu \mathrm{m}^{2}\right)$ between groups ( $p=0.019$; Fig. $4 \mathrm{~b}$ ). Both naïve and sham piglets had median injured neuron counts of 0 (IQR for naïve: $0-0.1$; IQR for sham: $0-0 ; p=0.524$ ).

Naïve $(n=6)$ and sham normothermic $(n=8)$ piglets exhibited similar numbers of viable neurons $(p=0.311)$ and apoptotic profiles $(p=1.00)$ in the posterior putamen (Fig. 4c, d). Median injured neuron counts were 2.1 (IQR $0.2-3.7$ ) in naïve and 0.6 (IQR $0.2-2.6$ ) in sham piglets $(p=0.755)$.

There were no differences in viable neuron $(p=0.852$; Fig 4 e) or apoptotic profile ( $p=0.651$; Fig $4 \mathrm{f}$ ) counts in the motor cortex in naïve $(n=6)$ or sham normothermic $(n=8)$ piglets. Median injured neuron counts were 0 (IQR $0-0)$ in naïve and 0 (IQR $0-0)$ in sham piglets $(p=$ 0.955). Therefore, the fentanyl-nitrous oxide anesthetic did not increase apoptosis above the normal developmental level observed in naïve piglets, and it had minimal effect on the number of viable or injured neurons.

\section{Effects of HI and Temperature on Cell Death}

\section{Anterior Putamen}

Absolute cell counts in the putamen for each experimental group are presented in Table 1. In the anterior putamen, $\mathrm{HI}$ and temperature significantly interacted in their effects on the number of viable neurons $(p<0.001$; Fig. 5a). HI $(p=0.668)$ and temperature $(p=0.168)$ did not individually affect viable neuron counts. In post hoc pairwise comparisons, HI followed by normothermia decreased the number of viable neurons to below that of HI hypothermia $(p<0.001)$ and HI rewarming $(p<0.001)$. Among sham piglets, both sustained hypothermia $(p<$ $0.001)$ and hypothermia with rewarming $(p=0.019)$ decreased viable neuron counts to below that of sham normothermia. Comparisons between the normothermic groups showed a decrease in the number of viable neurons in HI pigs to below that of shams $(p<0.001)$. After sustained hypothermia, shams had fewer viable neurons than HI pigs $(p<0.001)$. Finally, sham rewarmed pigs had fewer viable neurons than HI rewarmed pigs $(p=0.038)$.

$\mathrm{HI}$ independently affected the number of apoptotic profiles in the anterior putamen $(p=0.004)$ and $\mathrm{HI}$ and temperature significantly interacted ( $p=0.003$; Fig. $5 b)$. Cooling alone did not have an independent effect ( $p=$ 0.088 ). Post hoc comparisons among sham piglets showed that sustained hypothermia increased apoptosis above 

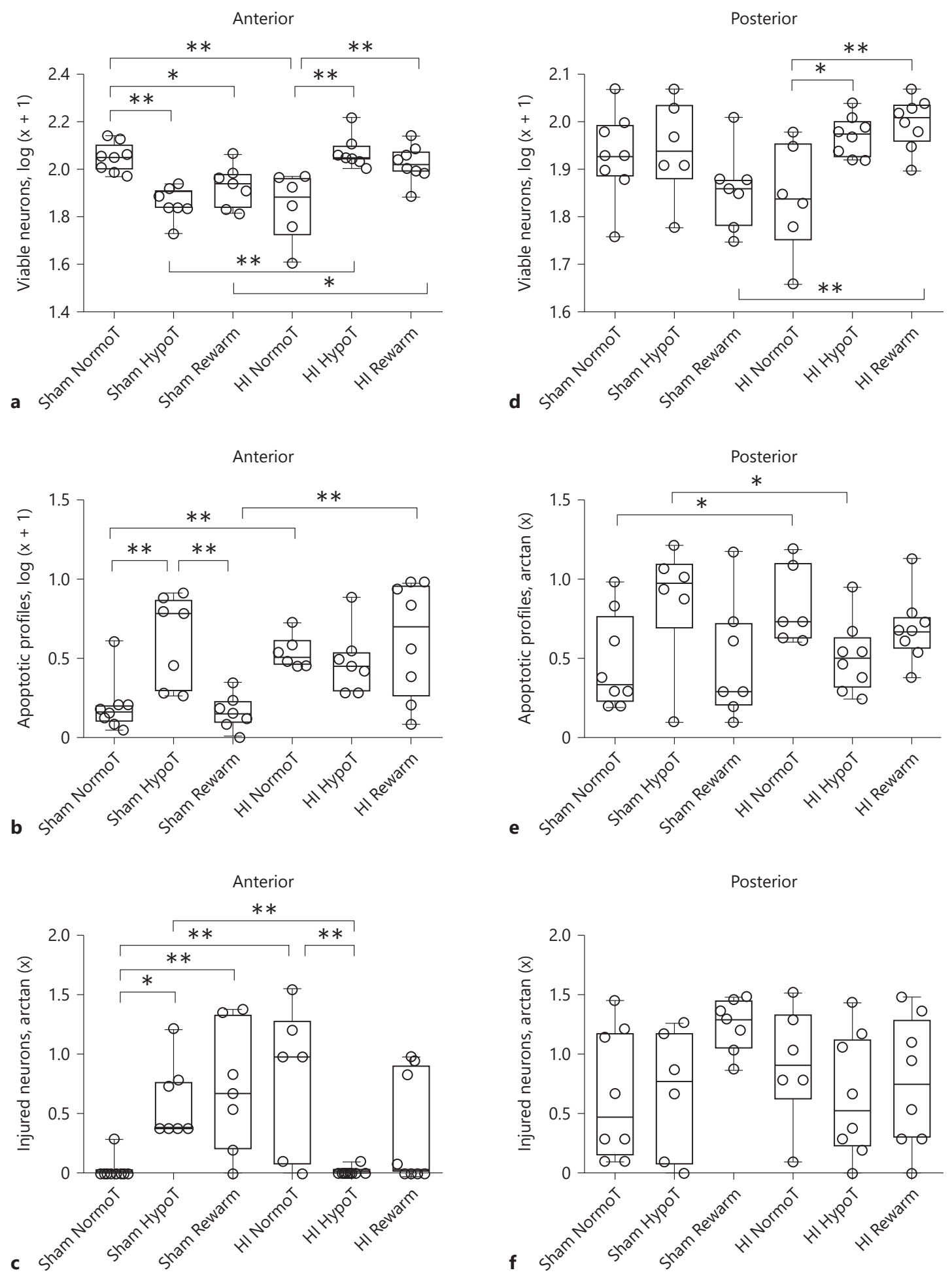

5

(For legend see next page.) 
that of hypothermia with rewarming $(p=0.002)$ or normothermia $(p=0.002)$. During normothermia, HI increased apoptosis above that of sham procedure $(p=$ $0.010)$. HI piglets that were rewarmed from hypothermia also had more apoptosis than rewarmed shams $(p<0.001)$.

The majority of injured neurons in the anterior putamen of HI piglets had classical ischemic necrotic morphology. HI $(p=0.620)$ and temperature $(p=0.334)$ did not independently affect neuronal injury but did significantly interact in their effect on the number of injured neurons ( $p<0.001$; Fig. 5 c). After HI, normothermic pigs had more injured neurons than did pigs with sustained hypothermia $(p=0.003)$. Sham piglets with sustained hypothermia $(p=0.017)$ and hypothermia with rewarming $(p=0.007)$ had increased neurodegeneration above that of normothermic shams. Normothermic HI pigs had more injured neurons than did sham pigs $(p=0.001)$. Finally, when comparing piglets that underwent sustained hypothermia, shams had more neuronal degeneration than did HI pigs $(p=0.008)$.

TUNEL staining in the anterior putamen confirmed some of the trends we observed by H\&E stain. Temperature and $\mathrm{HI}$ interacted in their effect on the number of TUNEL+ cells ( $p=0.035$; Fig. 6a). HI $(p=0.161)$ and temperature $(p=0.845)$ did not independently affect these counts. In post hoc pairwise comparisons, hypothermic shams had more TUNEL+ profiles than did normothermic shams $(p=0.033)$ and rewarmed shams $(p=$ $0.014)$. Shams had more cells with DNA fragmentation than did HI piglets during hypothermia $(p=0.024)$. Among piglets that had both TUNEL+ and H\&E apoptotic profile counts, correlation in classifying apoptosis was significant $(r=0.65, p<0.0001)$, with low bias and high agreement (Fig. 6b, c).

\section{Posterior Putamen}

In the posterior putamen, $\mathrm{HI}$ and cooling significantly interacted in their effect on the number of viable neurons
( $p=0.003$; Fig. 5d). Independently, HI $(p=0.322)$ and temperature $(p=0.098)$ did not affect viable neuron counts. Similar to our observations in the anterior putamen, HI hypothermia $(p=0.013)$ and HI hypothermia with rewarming $(p=0.004)$ increased the number of viable neurons to exceed that of HI normothermia. After rewarming, shams had fewer viable neurons than did HI pigs $(p=0.003)$

$\mathrm{HI}$ and temperature interacted in their effect on apoptosis $(p=0.008$; Fig. $5 \mathrm{e})$. HI $(p=0.459)$ and temperature $(p=0.655)$ did not independently affect apoptosis. HI normothermic pigs had more apoptosis than did sham normothermic pigs $(p=0.032)$. By contrast, sham hypothermic pigs had more apoptosis than HI hypothermic pigs $(p=0.032)$. HI and temperature did not affect the number of injured neurons in the posterior putamen ( $p>0.05$ for all comparisons; Fig. 5f). As in the anterior putamen, the majority of injured neurons in the posterior putamen were morphologically ischemic necrotic.

Findings on TUNEL stain were also consistent with some of our observations on H\&E stain in the posterior putamen. Temperature independently affected the number of TUNEL+ cells $(p<0.001)$, and there was an interactive effect of $\mathrm{HI}$ and cooling $(p<0.001)$. HI did not independently affect the number of TUNEL+ cells $(p=0.496)$. In post hoc pairwise analyses, HI normothermic pigs had more TUNEL+ profiles than did sham normothermic pigs ( $p<0.001$; Fig. $6 \mathrm{~d})$. Conversely, sham hypothermic pigs had more TUNEL+ profiles than did HI hypothermic, sham normothermic, and sham rewarmed pigs ( $p<0.001$ for all). Hypothermia and hypothermia with rewarming after HI was associated with fewer TUNEL+ cells than was normothermic recovery ( $p=0.003$ for both). When both TUNEL and H\&E were performed, correlation between TUNEL+ cells and apoptotic profiles was significant $(r=0.57, p<0.0001)$ with low bias and high agreement (Fig. 6e, f).
Fig. 5. The effects of temperature and hypoxia-ischemia (HI) on viable neuron $(\mathbf{a}, \mathbf{d})$, apoptotic profile $(\mathbf{b}, \mathbf{e})$, and injured neuron $(\mathbf{c}, \mathbf{f})$ counts in the anterior $(\mathbf{a}-\mathbf{c})$ and posterior $(\mathbf{d}-\mathbf{f})$ putamen on hematoxylin and eosin ( $\mathrm{H} \& \mathrm{E})$-stained sections. a $\mathrm{HI}$ and temperature significantly interacted in their effect on the number of viable neurons $(p<0.001)$. b HI independently affected the number of apoptotic profiles $(p=0.004)$, and $\mathrm{HI}$ and temperature significantly interacted $(p=0.003)$. c HI and temperature significantly interacted in their effect on injured neurons $(p<0.001)$. $\mathbf{d}$ In the posterior putamen, $\mathrm{HI}$ and temperature significantly interacted in their effect on the number of viable neurons $(p=0.003)$. e HI and temperature interacted in their effect on apoptosis $(p=0.008) . \mathbf{f} \mathrm{HI}$ and temperature did not affect the number of ischemic neurons in the posterior putamen ( $p>0.05$ for all comparisons). Each circle represents 1 piglet. Box plots with IQRs and 5-95th percentile whiskers are shown. Analyses were conducted by 2 -way analysis of variance and post hoc pairwise comparisons with Holm-Sidak tests. ${ }^{*} p<0.05$ and ${ }^{* *} p<0.01$. NormoT, sustained normothermia; HypoT, sustained hypothermia; Rewarm, hypothermia followed by rewarming.
Independent and Interactive Effects of HIE and Hypothermia in Neonatal Piglets
Dev Neurosci 2019;41:17-33

DOI: $10.1159 / 000496602$ 


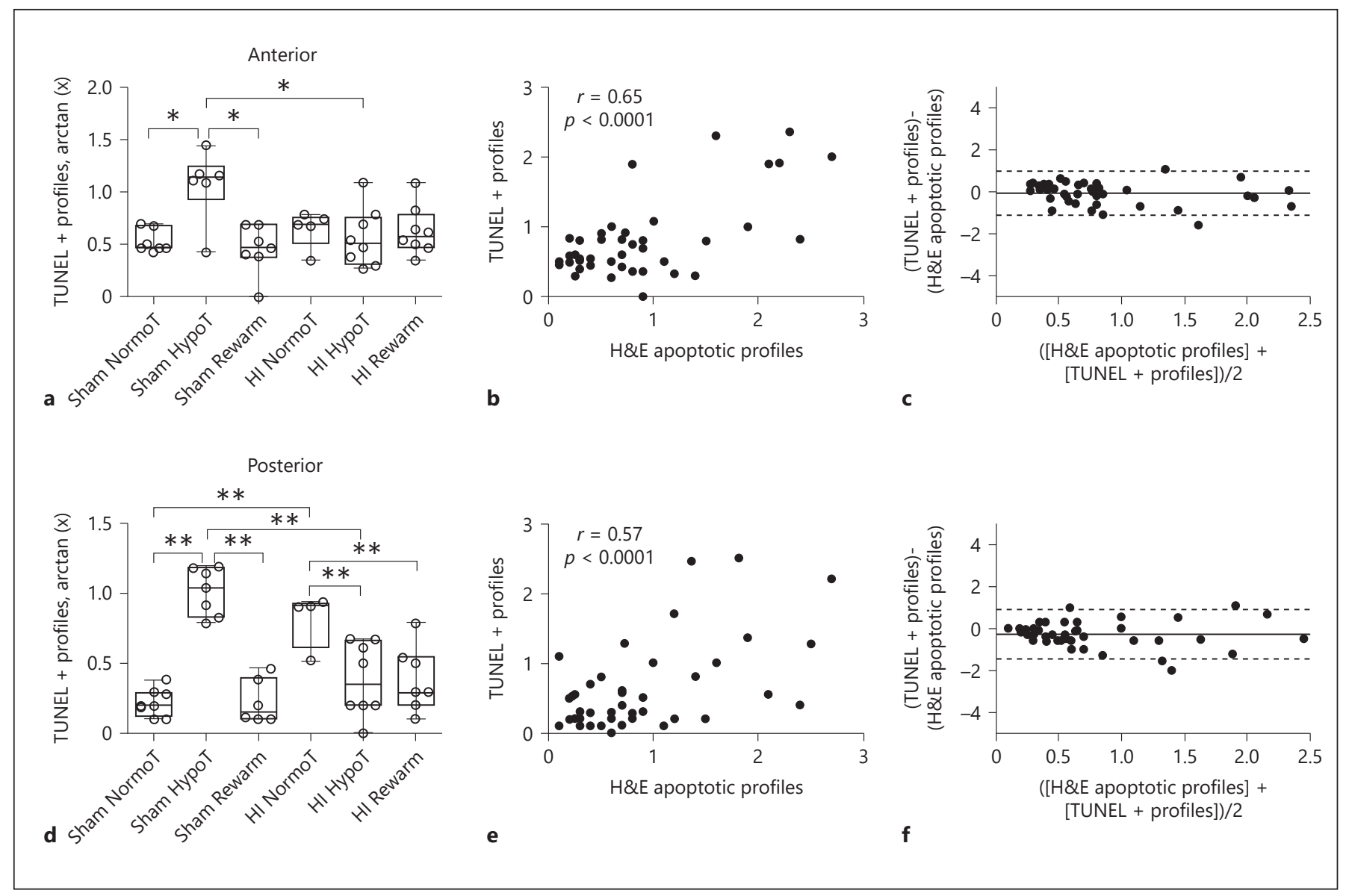

Fig. 6. Terminal deoxynucleotidyl transferase dUTP nick-end labeling (TUNEL) staining to identify cell death in the anterior putamen $(\mathbf{a}-\mathbf{c})$ and posterior putamen $(\mathbf{d}-\mathbf{f})$. a Temperature and hypoxiaischemia (HI) interacted in their effect on the number of TUNEL+ cells $(p=0.035) .{ }^{*} p<0.05$. b Interrater reliability analysis showed significant correlation in counting TUNEL+ cells and apoptotic profiles by hematoxylin and eosin $(\mathrm{H} \& \mathrm{E})$ staining at the anterior level $(r=0.65, p<0.0001)$. c Bland-Altman plot for TUNEL+ cells and apoptotic profiles by $\mathrm{H} \& \mathrm{E}$ stain at the anterior level. Bias is shown by the solid line. The $95 \%$ limits of agreement are shown by dotted lines. Bias was near-zero with high agreement. $\mathbf{d}$ Temperature independently affected the number of TUNEL+ cells $(p<0.001)$, and HI

\section{Motor Cortex}

HI injury independently ( $p=0.007)$ and interactively with temperature $(p<0.001)$ affected the number of viable cortical neurons in layers 2 and 3 (Fig. 7a). Temperature alone did not affect the viable neuron count $(p=$ 0.390). In post hoc comparisons, HI hypothermic piglets had more viable neurons than did sham hypothermic piglets $(p<0.001)$. Normothermic shams also had more viable neurons than did hypothermic $(p=0.002)$ and rewarmed shams $(p=0.025)$. and cooling had an interactive effect $(p<0.001)^{* *} p<0.01$. e Interrater reliability analysis showed significant correlation in counting TUNEL+ cells and apoptotic profiles by H\&E at the posterior level $(r=0.57, p<0.0001)$. f Bland-Altman plot for TUNEL+ cells and apoptotic profiles by H\&E stain at the posterior level. Bias is shown by the solid line. The $95 \%$ limits of agreement are shown by dotted lines. Bias was near-zero with high agreement. Each circle represents 1 piglet. Data in $(\mathbf{a}, \mathbf{d})$ are graphed as box plots with IQRs and 5-95th percentile whiskers. Analyses in (a, d) were conducted by 2-way analysis of variance and post hoc pairwise comparisons with HolmSidak tests. NormoT, sustained normothermia; HypoT, sustained hypothermia; Rewarm, hypothermia followed by rewarming.

HI $(p<0.001)$ and temperature $(p=0.009)$ independently and interactively $(p<0.001)$ affected the number of apoptotic profiles (Fig. 7b). HI hypothermia increased apoptosis above that of sham hypothermia $(p=0.020)$. The combination of HI, hypothermia, and rewarming increased apoptosis to exceed that of sham rewarming $(p<0.001)$, HI hypothermia $(p<0.001)$, and HI normothermia $(p<0.001)$.

Many injured neurons in the motor cortex showed morphologic signs of classical ischemic necrosis, whereas others had cytopathology that was primarily focused in 


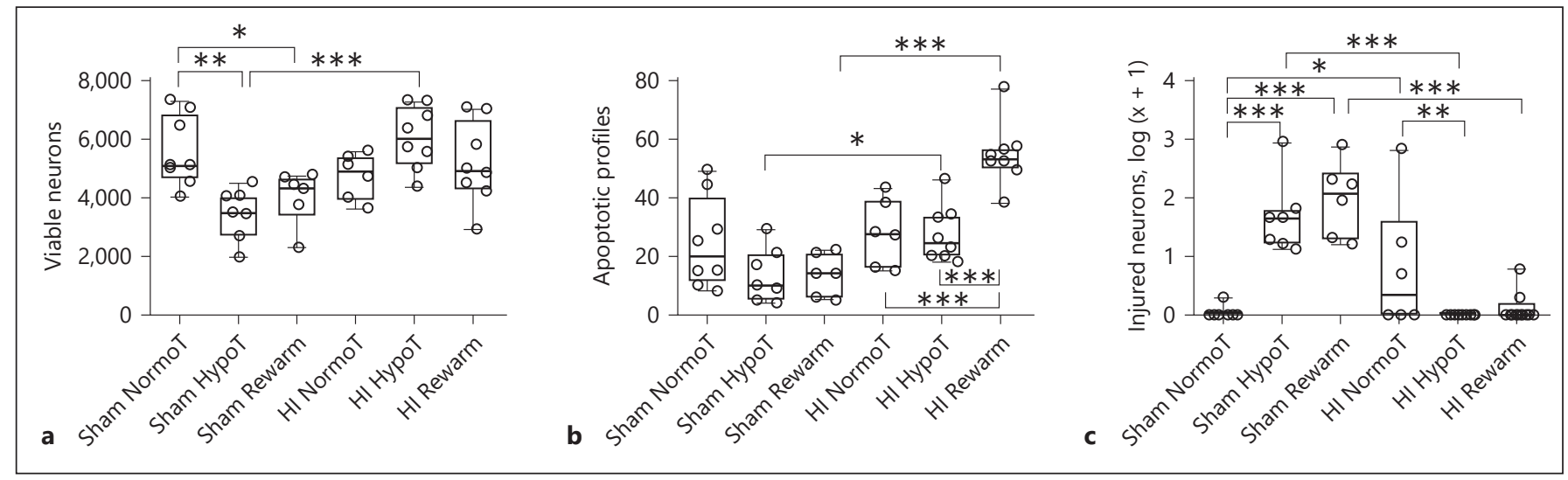

Fig. 7. The effect of temperature and hypoxia-ischemia (HI) on viable neuron (a), apoptotic profile (b), and injured neuron (c) counts in the motor cortex. a HI had an independent $(p=0.007)$ and interactive effect with temperature $(p<0.001)$ on the number of viable neurons. b HI $(p<0.001)$ and temperature $(p=0.009)$ independently and interactively $(p<0.001)$ affected the number of apoptotic profiles. c HI $(p<0.001)$ and temperature $(p=0.014)$

the cytoplasm (eosinophilic cytoplasm with vacuoles) without fulminant nuclear degeneration (Fig 2b, c). We classified both of these cell types as injured for the analysis. The injured neurons with eosinophilic and vacuolated cytoplasm, but without overt nuclear signs of ischemic necrosis, were predominately in sham piglets.

HI $(p<0.001)$ and temperature $(p=0.014)$ independently and interactively $(p<0.001)$ affected injured neuron counts (Fig. 7c). Normothermic HI piglets had more injured neurons than did normothermic shams $(p=0.015)$. $\mathrm{HI}$ hypothermia reduced the number of injured neurons to below that of HI normothermia $(p=0.003)$. However, sham hypothermia and sham rewarming increased the number of injured neurons to exceed that of $\mathrm{HI}$ piglets with the same temperature treatment ( $p<0.001$ for both). Among the sham groups, sustained hypothermia and hypothermia with rewarming increased the injured neuron count to above that of normothermia ( $p<0.001$ for both).

Protein Markers of Cell Death, Inflammation, and the Unfolded Protein Response in the Putamen

We performed western blotting for protein markers of neuronal viability, cell death, inflammation, and the unfolded protein response. Among the experimental groups, we found no differences in the expression of NeuN or cleaved caspase-3 ( $p>0.05$ for both; online suppl. Fig. 1a, b; see www.karger.com/doi/10.1159/000496602 for all online suppl. material); TNFa, CD95, nitrotyrosine, or Iba1 independently and interactively $(p<0.001)$ affected injured neuron counts. Each circle represents 1 piglet. Box plots with IQRs and 5-95th percentile whiskers are shown. Analyses were conducted by 2 -way analysis of variance and post-hoc pairwise comparisons with Holm-Sidak tests. ${ }^{*} p<0.05,{ }^{* *} p<0.01$, and ${ }^{* * *} p<0.001$. NormoT, sustained normothermia; HypoT, sustained hypothermia; Rewarm, hypothermia followed by rewarming.
( $p>0.05$ for all; online suppl. Fig. 2a-d); or Hsp70, ERN1, PERK, or pERN1 ( $p>0.05$ for all; online suppl. Fig. 3a-d).

\section{Vasopressors}

One piglet (sham rewarm) received dopamine. Five piglets received phenylephrine (2 $\mathrm{HI}$ normothermia, $1 \mathrm{HI}$ hypothermia, and $2 \mathrm{HI}$ rewarm). In the anterior putamen, the number of viable neurons $(p=0.813)$, apoptotic profiles $(p=0.107)$, and injured neurons $(p=0.624)$ did not differ between pigs that received phenylephrine and those that did not receive a vasopressor. Phenylephrine also did not affect the number of viable neurons ( $p=0.927)$, apoptotic profiles $(p=1.000)$, or injured neurons $(p=0.599)$ in the posterior putamen relative to those piglets that did not receive a vasopressor. Similarly, in the motor cortex, administration of phenylephrine did not affect the number of viable neurons $(p=0.924)$, apoptotic profiles $(p=$ $0.507)$, or injured neurons $(p=0.182)$ compared with piglets that did not receive phenylephrine.

\section{Discussion}

We identified several findings relevant to the effects of hypothermia on the moderately HI-injured and uninjured developing brain. After HI, sustained hypothermia and hypothermia with rewarming preserved viable neurons in the putamen to exceed that of normothermia, in 
part by preventing neuronal ischemic necrosis in the anterior putamen. However, hypothermia did not prevent neuronal ischemic necrosis in the posterior putamen nor did it protect against an $\mathrm{HI}$-induced increase in apoptosis in the anterior putamen, posterior putamen, or motor cortex. Cooling and rewarming increased neuronal injury in sham piglets in both the putamen and motor cortex. The reduction in viable neuron counts in the anterior putamen and motor cortex after sham hypothermia and rewarming further suggested that the degenerating cells were neurons. In these areas, the degree of neuronal degeneration was such that hypothermic shams had lower viable neuron counts than the hypothermic HI pigs. Further, sham hypothermia was associated with more apoptosis than HI hypothermia in the posterior putamen. These results were supported by TUNEL assay. Thus, we identify independent and interactive effects between moderate $\mathrm{HI}$ and temperature management in the developing brain that are region specific after $27 \mathrm{~h}$ of hypothermia. The potential for regional brain differences suggest that clinical HIE studies should measure injury of specific brain regions [30] in addition to using global injury scores [31].

Our study reveals new information on the regional vulnerability to $\mathrm{HI}$ and the therapeutic efficacy and potential off-target effects of targeted temperature management. We found that hypothermia protected the anterior putamen specifically from ischemic necrosis after HI but not the posterior putamen. Though the finding that hypothermia protects the piglet striatum after $\mathrm{HI}$ is not new [10], the finding that hypothermic protection from necrotic cell death can vary intra-regionally is new. This outcome is perhaps explained by differences in the metabolism and connectivity of these regions. Metabolic mapping of mitochondrial cytochrome c oxidase (complex IV) demonstrates higher activity in the posterior putamen compared to that of the anterior putamen [14]. Thus, hypothermia might be less effective at protecting brain regions with greater metabolic demands possibly because of a more rapid commitment to cell death prior to the onset of hypothermia at $2 \mathrm{~h}[13,23]$. Further, an interesting corollary is that the afferent connections of the anterior putamen and posterior putamen differ, particularly regarding corticostriatal connectivity in large animals and primates, including humans [32]. Generally, the entire cerebral cortex maps topographically onto the putamen in a pattern that follows the anterior-posterior axis. Thus, the frontal eye fields, supplementary motor area, premotor area, and primary motor cortices connect more anteriorly in putamen, while primary somatosen- sory, parietal, and visual cortices connect more with middle and posterior putamen in monkey and human [32]. Tract tracing and diffusion tensor imaging tractography studies in pig are uncommon [26], but our emerging data using cortical injection of lentivirus with genetically encoded fluorescent reporters suggest that piglet corticostriatal and thalamostriatal connectivity is similar to primates (L.J.M., P.T.S., J.K.L., unpublished observations). Another similarity to primates is the anterior-posterior pattern of dopamine receptor binding sites seen in the striatum of living piglets [33], which could also contribute to regional variability. Because the piglet model of neonatal HIE mimics that seen in human HIE [34], we are poised to more deeply understand the mechanisms of selective vulnerability and the potential effects of targeted temperature management on the immature brain.

Although the early form of neuronal death after HIE is ischemic necrosis, delayed neurodegeneration is more consistent with apoptosis and ongoing neuronal death likely contributes to long-term neurologic injury $[35,36]$. Though post-ischemic hypothermia suppresses apoptosis in rats [37, 38], hypothermia did not protect against apoptosis after $\mathrm{HI}$ in our swine model. Several possibilities could account for this finding. We delayed the induction of hypothermia by $2 \mathrm{~h}$ to mimic clinical delays, which may occur during resuscitation after birth injury or while transporting the neonate to a neonatal intensive care unit. We previously found that the essential molecular cascades for apoptosis can be activated within 15 min of excitotoxicity in a neonatal rat model [39]. Delaying hypothermia induction by $2-3 \mathrm{~h}$ attenuates the neuroprotection in the putamen afforded by immediate hypothermia after piglet HI $[40,41]$. Therefore, it is possible that the $2 \mathrm{~h}$ delay after injury contributed to the inability to protect against apoptotic cell death. Use of adjuvant therapies that specifically mitigate apoptosis could be one strategy to improve hypothermic neuroprotection.

Further, the ideal duration of hypothermia after $\mathrm{HI}$ is unknown. We studied up to $27 \mathrm{~h}$ of hypothermia, which is shorter than clinical hypothermia for treatment of HIE, but similar to that of other neonatal swine models [4043] and longer than that of rodent models. In an adult swine model of cardiac arrest, $48 \mathrm{~h}$ of hypothermia attenuated hippocampal apoptosis more than $24 \mathrm{~h}$ of hypothermia [44]. Because we did not test different durations of hypothermia, we do not know if longer periods would afford greater protection against apoptosis. We do not extend the duration of hypothermia in our neonatal piglets owing to neurotoxicity from prolonged anesthesia (unpublished data). However, additional studies of dif-
28

Dev Neurosci 2019;41:17-33 DOI: $10.1159 / 000496602$
O’Brien/Santos/Kulikowicz/Reyes/ Koehler/Martin/Lee 
ferent durations of hypothermia are needed. Fetal lamb models that maintain placental support from the mother may improve the ability to study long durations of hypothermia in more depth [45], including in uninjured developing brain. Because $\mathrm{HI}$ brain injury can evolve over weeks to months [46], long-term recovery studies in large, neonatal animal models with gyrencephalic brain and $\mathrm{HI}$ are also necessary.

Rewarming from hypothermia after $\mathrm{HI}$ increased apoptosis in the motor cortex [15] but not in the putamen. Rewarming is a high-risk period for complications and ongoing brain injury after HIE because it is associated with seizures [47], greater discontinuity on electroencephalogram [48], dysfunctional cerebrovascular autoregulation [25], and neuroinflammation [43, 45]. Although a fetal sheep model of HIE showed that slow rewarming reduced injury measured by EEG relative to rapid rewarming, the actual rewarming rates may be less important than the duration of hypothermia for neuronal protection [49].

As comfort with delivering therapeutic hypothermia grows, clinical hypothermia has been considered for neonatal diseases beyond moderate-to-severe HIE [2-6, 50]. Moreover, neonates without known brain injury require rewarming if they become inadvertently hypothermic, including low birthweight newborns [7] and neonates who undergo surgery [8]. Hypothermia is also used for neonatal cardiopulmonary bypass during repair of congenital heart defects. Thus, the independent effects of hypothermia and rewarming on the uninjured neonatal brain deserve thorough study.

We identified possible risks to the anterior putamen and motor cortex from hypothermia and rewarming in uninjured developing brain. In these areas, hypothermic and rewarmed shams had more injured neurons and fewer viable neurons than normothermic shams. Neuropathology in the striatum is concerning because of its key role in motor control, sensory-motor integration, learning and cognition, and emotional-social behavior [51]. Further, sham hypothermia was associated with increased apoptosis and a greater number of TUNEL-positive cells compared with those of sham normothermia and sham rewarming in the anterior putamen. This finding is consistent with our prior work in the subcortical white matter [19]. Because we selected only one time point after HI or sham procedure to quantify cell death, the hypothermic piglets received $27 \mathrm{~h}$ of hypothermia, whereas the rewarmed piglets received $18 \mathrm{~h}$ of hypothermia. It is possible that the additional $9 \mathrm{~h}$ at $34^{\circ} \mathrm{C}$ contributed to the increased apoptosis and suggests that pro-

Independent and Interactive Effects of HIE and Hypothermia in Neonatal Piglets longed hypothermia may have detrimental effects in uninjured brain.

We also observed cortical neuronal injury in sham piglets that received hypothermia including cytoplasmic vacuolization and eosinophilia (Fig. 2b, c). The fate of these injured cortical neurons is not known, and additional study with electron microscopy is needed. The biological basis for the sensitivity of the cerebral cortex to hypothermia merits exploration, but one possibility relates to the birthdate and maturation of these neurons. Layers 2 and 3 of neocortex are among the latest born neurons in primate brain [52] so this relative propinquity to cell cycle exiting and immaturity might impart vulnerability to cooling. However, early birthdate would not explain the vulnerability of the anterior putamen to hypothermia because these neurons are born much earlier than superficial cortical neurons [52, 53]. A surprising aspect of the corti$\mathrm{cal}$ and anterior putamen vulnerability to hypothermia was its mitigation by $\mathrm{HI}$, thus highlighting the potential interactions of their molecular physiologies.

The mechanisms by which hypothermia may contribute to neurodegeneration in the developing brain are unknown. In the absence of other injury, severe hypothermia is known to promote cell death by increasing production of reactive oxygen species [54], contributing to derangements in mitochondrial bioenergetics [55], and diminishing production of antioxidants [56]. Interestingly, some of these deleterious effects are absent in the presence of hypoxia or other brain injury [54, 57].

It is important to consider the potential combined effects of hypothermia and anesthesia on neuronal cytopathology. Anesthetized shams that received $29 \mathrm{~h}$ of normothermia had similar viable, apoptotic, and injured neuronal counts as naïve piglets. Therefore, during normothermia our anesthetic regimen alone did not cause apparent neuronal cytopathology, consistent with prior assessments of this anesthetic by several parameters [15, 19-21]. We chose the combination of fentanyl-nitrous oxide because previous work in newborn lambs demonstrated that this regimen provided anesthesia without decreasing the cerebral metabolic rate of oxygen [58], in contrast to many other anesthetic regimens. Because it is unethical to cool piglets in the absence of anesthesia given the risk of shivering, discomfort, and hemodynamic changes, we cannot comment on the effects of hypothermia without anesthesia. Hypothermia decreases neuronal metabolism [59], and it is possible that the cellular injury we observed is related to a synergistic effect between hypothermia and fentanyl-nitrous oxide. For instance, hypothermia during our anesthetic regimen could lower 
spontaneous cerebral electrical activity to below that of anesthesia alone. Whether very low electrical activity in these circumstances causes neuronal injury is not known and cannot be deciphered in our study.

Nonetheless, further studies on the interactions between hypothermia and sedation or anesthesia should be considered in the developing brain. Although 3 days of hypothermia in healthy adults rats did not produce adverse neurologic effects [60], data in neonatal brain are limited. The postnatal developing and adult rodent and nonhuman primate brains have many pronounced differences in ion channel glutamate receptor expression patterns $[61,62]$, neurotransmitters [51], and cell death [63, 64], including apoptosis. Thus, we recommend additional studies on the independent effects of hypothermia and rewarming on the developing brain.

We used western blotting in an attempt to validate our histologic measurements in the putamen, but the data did not support the histologic cell counts. Our sample sizes exceeded those from our previous study, which showed significant cleaved caspase-3 protein level differences in cortex after HI, hypothermia, and rewarming. However, that was in cerebral cortex where apoptosis is highly concentrated in a major cell-dense layer [15]. The inability to detect differences in levels of proteins involved in cell death, inflammation, or the unfolded protein response might relate to our use of a crude homogenate assay, which incorporates proteins from intrinsic neurons, white matter axons enriched in striatal bundles, glial cells, vascular cells, and blood-borne cells. The cellular resolution that is achieved with microscopy is lost with crude homogenate assays, and microscopic counting is a direct one-to-one metric. Furthermore, we assessed protein levels at a single time point which might not reflect upstream mechanisms activated shortly after HI injury.

Our study had several limitations. Although sufficiently powered for histologic outcomes, we used a small sample size and multiple treatment groups. Thus, our results must be replicated in other studies for further interpretation. Interrater reliability analyses showed higher bias for viable neuron counts than for apoptotic profile counts. The differences in viable neuron counts between the 2 investigators who conducted the microscopy were likely due to the different microscope fields that were counted in each pig. We could not ensure that the same microscope field was counted by each investigator. Additionally, we examined only male piglets. Rodent studies suggest that males may preferentially activate caspase-independent cell death, whereas females may activate caspase-dependent cell death and may be more resistant to HI $[65,66]$. The effects of sex on cell death after hypothermia and rewarming with and without $\mathrm{HI}$ merits study. Although we believe this model to be a moderate HI injury, we did not perform neurologic assessments and cannot comment on the long-term ramifications of this degree of neuronal loss. We have shown that although most cell death occurs before $24 \mathrm{~h}$ in the putamen, it does progress over $96 \mathrm{~h}$ in more severe models [13]. Whether moderate HI prolongs the delay in cell death in the putamen or cerebral cortex is unknown. The current standard of care for neonatal HIE is $72 \mathrm{~h}$ of hypothermia [1]. We only provided up to $27 \mathrm{~h}$ of hypothermia in this study. Longer experiments are necessary to more fully describe the effects of hypothermia on the developing brain. Finally, neonates are not exposed to $29 \mathrm{~h}$ of general anesthesia with nitrous oxide during hypothermia and rewarming as the piglets were in our experiments. We utilized our specific anesthetic regimen to ensure animal comfort.

\section{Conclusion}

Hypothermia after moderate HI preserved viable neurons in the putamen and protected against neuronal injury in the anterior putamen and motor cortex in neonatal swine. Hypothermia after HI did not prevent neuronal injury in the posterior putamen. Moreover, hypothermia initiated $2 \mathrm{~h}$ after injury did not protect against apoptotic cell death in either the putamen or motor cortex, and rewarming from hypothermia was associated with increased apoptosis in the motor cortex. After sham procedure, hypothermia was associated with increased neuronal injury in the anterior putamen and motor cortex with a congruent decrease in the number of viable neurons. The neuronal injury in the cortex was morphologically distinct from that in the putamen. Thus, $\mathrm{HI}$ and temperature have independent and interactive effects on neuronal pathology in this neonatal swine model. These effects may be region specific and likely involve different cell death mechanisms that warrant further study.

\section{Acknowledgments}

We are grateful to Claire Levine, MS, ELS, for her editorial assistance.

\section{Statement of Ethics}

Animal experiments conform to internationally accepted standards and have been approved by the appropriate institutional review body.
Dev Neurosci 2019;41:17-33 DOI: $10.1159 / 000496602$
O’Brien/Santos/Kulikowicz/Reyes/ Koehler/Martin/Lee 


\section{Disclosure Statement}

The authors declare no conflicts of interest.

\section{Funding Sources}

This work was supported by NIH grants T32HL125239 (C.E.O.), K08NS080984 (J.K.L.), R01 NS107417 (J.K.L.), R01 NS060703 (R.C.K. and L.J.M.), R21 NS095036 (R.C.K.), R01 HL139543 (R.C.K.), and AG05146 (L.J.M.); BrightFocus Foundation A2015332S (L.J.M.); and the American Heart Association Transformational Project Award (J.K.L.).

\section{Appendix 1}

Piglets Not Analyzed by Histology

We used tissue from our past studies on cortical and white matter injury $[15,19]$. For the current study, H\&E cell counts could not be conducted in the anterior putamen of one naïve pig and one HI hypothermia pig, and in the posterior putamen of one sham hypothermia pig because tissue at the appropriate anatomic level was unavailable. TUNEL-stained slides from the anterior putamen were not available for one sham normothermia, one sham hypothermia, and one HI normothermia piglet because of tissue damage or incomplete stain. TUNEL-stained slides were not available for one sham rewarm piglet, two HI normothermia piglets, and one HI rewarm piglet in the posterior putamen because of tissue damage.

\section{References}

1 Shankaran S, Laptook AR, Ehrenkranz RA, Tyson JE, McDonald SA, Donovan EF, et al.; National Institute of Child Health and $\mathrm{Hu}-$ man Development Neonatal Research Network. Whole-body hypothermia for neonates with hypoxic-ischemic encephalopathy. N Engl J Med. 2005 Oct;353(15):1574-84.

2 Lodygensky GA, Battin MR, Gunn AJ. Mild neonatal encephalopathy-how, when, and how much to treat? JAMA Pediatr. 2018 Jan; 172(1):3-4.

3 Kracer B, Hintz SR, Van Meurs KP, Lee HC. Hypothermia therapy for neonatal hypoxic ischemic encephalopathy in the state of California. J Pediatr. 2014 Aug;165(2):267-73.

4 Azzopardi D, Strohm B, Linsell L, Hobson A, Juszczak E, Kurinczuk JJ, et al.; UK TOBY Cooling Register. Implementation and conduct of therapeutic hypothermia for perinatal asphyxial encephalopathy in the UK-analysis of national data. PLoS One. 2012;7(6):e38504.

5 Oliveira V, Singhvi DP, Montaldo P, Lally PJ, Mendoza J, Manerkar S, et al. Therapeutic hypothermia in mild neonatal encephalopathy: a national survey of practice in the UK. Arch Dis Child Fetal Neonatal Ed. 2018 Jul 103(4):F388-90.

6 Hall NJ, Eaton S, Peters MJ, Hiorns MP, Alexander N, Azzopardi DV, et al. Mild controlled hypothermia in preterm neonates with advanced necrotizing enterocolitis. Pediatrics. 2010 Feb;125(2):e300-8.

7 Feldman A, De Benedictis B, Alpan G, La Gamma EF, Kase J. Morbidity and mortality associated with rewarming hypothermic very low birth weight infants. J Neonatal Perinatal Med. 2016 Sep;9(3):295-302.

8 Engorn BM, Kahntroff SL, Frank KM, Singh S, Harvey HA, Barkulis CT, et al. Perioperative hypothermia in neonatal intensive care unit patients: effectiveness of a thermoregulation intervention and associated risk factors. Paediatr Anaesth. 2017 Feb;27(2):196204

Independent and Interactive Effects of HIE and Hypothermia in Neonatal Piglets
9 Zhu J, Wang B, Lee JH, Armstrong JS, Kulikowicz E, Bhalala US, et al. Additive Neuroprotection of a 20-HETE Inhibitor with Delayed Therapeutic Hypothermia after HypoxiaIschemia in Neonatal Piglets. Dev Neurosci. 2015;37(4-5):376-89.

10 Agnew DM, Koehler RC, Guerguerian AM, Shaffner DH, Traystman RJ, Martin LJ, et al. Hypothermia for 24 hours after asphyxic cardiac arrest in piglets provides striatal neuroprotection that is sustained 10 days after rewarming. Pediatr Res. 2003 Aug;54(2):25362.

11 Yang ZJ, Torbey M, Li X, Bernardy J, Golden WC, Martin LJ, et al. Dopamine receptor modulation of hypoxic-ischemic neuronal injury in striatum of newborn piglets. J Cereb Blood Flow Metab. 2007 Jul;27(7):1339-51.

12 Martin LJ, Brambrink AM, Price AC, Kaiser A, Agnew DM, Ichord RN, et al. Neuronal death in newborn striatum after hypoxiaischemia is necrosis and evolves with oxidative stress. Neurobiol Dis. 2000 Jun;7(3):16991.

13 Martin LJ, Brambrink AM, Lehmann C, Portera-Cailliau C, Koehler R, Rothstein J, et al. Hypoxia-ischemia causes abnormalities in glutamate transporters and death of astroglia and neurons in newborn striatum. Ann Neurol. 1997 Sep;42(3):335-48.

14 Martin LJ, Brambrink A, Koehler RC, Traystman RJ. Primary sensory and forebrain motor systems in the newborn brain are preferentially damaged by hypoxia-ischemia. J Comp Neurol. 1997 Jan;377(2):262-85.

15 Wang B, Armstrong JS, Lee JH, Bhalala U, Kulikowicz E, Zhang H, et al. Rewarming from therapeutic hypothermia induces cortical neuron apoptosis in a swine model of neonatal hypoxic-ischemic encephalopathy. J Cereb Blood Flow Metab. 2015 May;35(5): 781-93.
16 Huang BY, Castillo M. Hypoxic-ischemic brain injury: imaging findings from birth to adulthood. Radiographics. 2008 Mar-Apr; 28(2):417-39.

17 Trivedi SB, Vesoulis ZA, Rao R, Liao SM, Shimony JS, McKinstry RC, et al. A validated clinical MRI injury scoring system in neonatal hypoxic-ischemic encephalopathy. Pediatr Radiol. 2017 Oct;47(11):1491-9.

18 Groenendaal F, de Vries LS. Fifty years of brain imaging in neonatal encephalopathy following perinatal asphyxia. Pediatr Res. 2017 Jan;81(1-2): 150-5.

19 Wang B, Armstrong JS, Reyes M, Kulikowicz E, Lee JH, Spicer D, et al. White matter apoptosis is increased by delayed hypothermia and rewarming in a neonatal piglet model of hypoxic ischemic encephalopathy. Neuroscience. 2016 Mar;316:296-310.

20 Lee JK, Wang B, Reyes M, Armstrong JS, Kulikowicz E, Santos PT, et al. Hypothermia and Rewarming Activate a Macroglial Unfolded Protein Response Independent of HypoxicIschemic Brain Injury in Neonatal Piglets. Dev Neurosci. 2016;38(4):277-94.

21 Santos PT, O'Brien CE, Chen MW, Hopkins $\mathrm{CD}$, Adams S, Kulikowicz E, et al. Proteasome Biology Is Compromised in White Matter After Asphyxic Cardiac Arrest in Neonatal Piglets. J Am Heart Assoc. 2018 Oct;7(20): e009415.

22 Larson AC, Jamrogowicz JL, Kulikowicz E, Wang B, Yang ZJ, Shaffner DH, et al. Cerebrovascular autoregulation after rewarming from hypothermia in a neonatal swine model of asphyxic brain injury. J Appl Physiol (1985). 2013 Nov; 115(10): 1433-42.

23 Mueller-Burke D, Koehler RC, Martin LJ. Rapid NMDA receptor phosphorylation and oxidative stress precede striatal neurodegeneration after hypoxic ischemia in newborn piglets and are attenuated with hypothermia. Int J Dev Neurosci. 2008 Feb;26(1) $67-76$. 
24 Azzopardi D, Brocklehurst P, Edwards D, Halliday $\mathrm{H}$, Levene $\mathbf{M}$, Thoresen $\mathrm{M}$, et al.; TOBY Study Group. The TOBY Study. Whole body hypothermia for the treatment of perinatal asphyxial encephalopathy: a randomised controlled trial. BMC Pediatr. 2008 Apr;8(1):17.

25 Burton VJ, Gerner G, Cristofalo E, Chung SE, Jennings JM, Parkinson C, et al. A pilot cohort study of cerebral autoregulation and 2-year neurodevelopmental outcomes in neonates with hypoxic-ischemic encephalopathy who received therapeutic hypothermia. BMC Neurol. 2015 Oct;15(1):209.

26 Jelsing J, Hay-Schmidt A, Dyrby T, Hemmingsen R, Uylings HB, Pakkenberg B. The prefrontal cortex in the Göttingen minipig brain defined by neural projection criteria and cytoarchitecture. Brain Res Bull. 2006 Oct;70(4-6):322-36.

27 Northington FJ, Zelaya ME, O'Riordan DP, Blomgren K, Flock DL, Hagberg H, et al. Failure to complete apoptosis following neonatal hypoxia-ischemia manifests as "continuum" phenotype of cell death and occurs with multiple manifestations of mitochondrial dysfunction in rodent forebrain. Neuroscience. 2007 Nov;149(4):82233.

28 Lee JK, Yang ZJ, Wang B, Larson AC, Jamrogowicz JL, Kulikowicz E, et al. Noninvasive autoregulation monitoring in a swine model of pediatric cardiac arrest. Anesth Analg. 2012 Apr;114(4):825-36

29 Brambrink AM, Martin LJ, Hanley DF, Becker KJ, Koehler RC, Traystman RJ. Effects of the AMPA receptor antagonist NBQX on outcome of newborn pigs after asphyxic cardiac arrest. J Cereb Blood Flow Metab. 1999 Aug; 19(8):927-38

30 Tekes A, Poretti A, Scheurkogel MM, Huisman TA, Howlett JA, Alqahtani E, et al. Apparent diffusion coefficient scalars correlate with near-infrared spectroscopy markers of cerebrovascular autoregulation in neonates cooled for perinatal hypoxic-ischemic injury. AJNR Am J Neuroradiol. 2015 Jan;36(1):18893.

31 Carrasco M, Perin J, Jennings JM, Parkinson C, Gilmore MM, Chavez-Valdez R, et al. Cerebral Autoregulation and Conventional and Diffusion Tensor Imaging Magnetic Resonance Imaging in Neonatal Hypoxic-Ischemic Encephalopathy. Pediatr Neurol. 2018 May;82:36-43.

32 Neggers SF, Zandbelt BB, Schall MS, Schall JD. Comparative diffusion tractography of corticostriatal motor pathways reveals differences between humans and macaques. J Neurophysiol. 2015 Apr;113(7):2164-72.

33 Rosa-Neto P, Doudet DJ, Cumming P. Gradients of dopamine D1- and D2/3-binding sites in the basal ganglia of pig and monkey measured by PET. Neuroimage. 2004 Jul;22(3): 1076-83.
34 Maller AI, Hankins LL, Yeakley JW, Butler IJ. Rolandic type cerebral palsy in children as a pattern of hypoxic-ischemic injury in the fullterm neonate. J Child Neurol. 1998 Jul;13(7): 313-21.

35 Nakajima W, Ishida A, Lange MS, Gabrielson KL, Wilson MA, Martin LJ, et al. Apoptosis has a prolonged role in the neurodegeneration after hypoxic ischemia in the newborn rat. J Neurosci. 2000 Nov;20(21):7994-8004.

36 Northington FJ, Ferriero DM, Flock DL, Martin LJ. Delayed neurodegeneration in neonatal rat thalamus after hypoxia-ischemia is apoptosis. J Neurosci. 2001 Mar;21(6):1931-8.

37 Xiong M, Cheng GQ, Ma SM, Yang Y, Shao $\mathrm{XM}$, Zhou WH. Post-ischemic hypothermia promotes generation of neural cells and reduces apoptosis by Bcl-2 in the striatum of neonatal rat brain. Neurochem Int. 2011 May; 58(6):625-33

38 Fan J, Cai S, Zhong H, Cao L, Hui K, Xu M, et al. Therapeutic hypothermia attenuates global cerebral reperfusion-induced mitochondrial damage by suppressing dynamin-related protein 1 activation and mitochondria-mediated apoptosis in a cardiac arrest rat model. Neurosci Lett. 2017 Apr;647:45-52.

39 LokJ, Martin LJ. Rapid subcellular redistribution of Bax precedes caspase- 3 and endonuclease activation during excitotoxic neuronal apoptosis in rat brain. J Neurotrauma. 2002 Jul;19(7):815-28.

40 Karlsson M, Tooley JR, Satas S, Hobbs CE, Chakkarapani E, Stone J, et al. Delayed hypothermia as selective head cooling or whole body cooling does not protect brain or body in newborn pig subjected to hypoxia-ischemia. Pediatr Res. 2008 Jul;64(1):74-8.

41 Tooley JR, Satas S, Porter H, Silver IA, Thoresen M. Head cooling with mild systemic hypothermia in anesthetized piglets is neuroprotective. Ann Neurol. 2003 Jan;53(1):6572.

42 Kerenyi A, Kelen D, Faulkner SD, Bainbridge A, Chandrasekaran M, Cady EB, et al. Systemic effects of whole-body cooling to $35^{\circ} \mathrm{C}$, $33.5^{\circ} \mathrm{C}$, and $30^{\circ} \mathrm{C}$ in a piglet model of perinatal asphyxia: implications for therapeutic hypothermia. Pediatr Res. 2012 May;71(5): 573-82.

43 Rocha-Ferreira E, Kelen D, Faulkner S, Broad $\mathrm{KD}$, Chandrasekaran M, Kerenyi Á, et al. Systemic pro-inflammatory cytokine status following therapeutic hypothermia in a piglet hypoxia-ischemia model. J Neuroinflammation. 2017 Mar; 14(1):44.

44 Suh GJ, Kwon WY, Kim KS, Lee HJ, Jeong KY, Jung YS, et al. Prolonged therapeutic hypothermia is more effective in attenuating brain apoptosis in a Swine cardiac arrest model. Crit Care Med. 2014 Feb;42(2):e132-42.

45 Davidson JO, Draghi V, Whitham S, Dhillon SK, Wassink G, Bennet L, et al. How long is sufficient for optimal neuroprotection with cerebral cooling after ischemia in fetal sheep? J Cereb Blood Flow Metab. 2018 Jun;38(6):1047-59.
46 Geddes R, Vannucci RC, Vannucci SJ. Delayed cerebral atrophy following moderate hypoxia-ischemia in the immature rat. Dev Neurosci. 2001;23(3):180-5.

47 Birca A, Lortie A, Birca V, Decarie JC, Veilleux A, Gallagher A, et al. Rewarming affects EEG background in term newborns with hypoxic-ischemic encephalopathy undergoing therapeutic hypothermia. Clin Neurophysiol. 2016 Apr;127(4):2087-94.

48 Lee JK, Poretti A, Perin J, Huisman TA, Parkinson C, Chavez-Valdez R, et al. Optimizing cerebral autoregulation may decrease neonatal regional hypoxic-ischemic brain injury. Dev Neurosci. 2017;39(1-4):248-56.

49 Davidson JO, Wassink G, Draghi V, Dhillon SK, Bennet L, Gunn AJ. Limited benefit of slow rewarming after cerebral hypothermia for global cerebral ischemia in near-term fetal sheep. J Cereb Blood Flow Metab. 2018 Aug;X18791631.

50 Lichter-Konecki U, Nadkarni V, Moudgil A, Cook N, Poeschl J, Meyer MT, et al. Feasibility of adjunct therapeutic hypothermia treatment for hyperammonemia and encephalopathy due to urea cycle disorders and organic acidemias. Mol Genet Metab. 2013 Aug; 109(4):354-9.

51 Martin LJ, Cork LC. The non-human primate striatum undergoes marked prolonged remodeling during postnatal development. Front Cell Neurosci. 2014 Sep;8:294.

52 Rakic P. Evolution of the neocortex: a perspective from developmental biology. Nat Rev Neurosci. 2009 Oct;10(10):724-35.

53 Brand S, Rakic P. Genesis of the primate neostriatum: $[3 \mathrm{H}]$ thymidine autoradiographic analysis of the time of neuron origin in the rhesus monkey. Neuroscience. 1979;4(6): 767-78.

54 Rauen U, Polzar B, Stephan H, Mannherz HG, de Groot H. Cold-induced apoptosis in cultured hepatocytes and liver endothelial cells: mediation by reactive oxygen species. FASEB J. 1999 Jan;13(1):155-68.

55 Riess ML, Camara AK, Kevin LG, An J, Stowe $\mathrm{DF}$. Reduced reactive $\mathrm{O} 2$ species formation and preserved mitochondrial $\mathrm{NADH}$ and $[\mathrm{Ca} 2+]$ levels during short-term 17 degrees $\mathrm{C}$ ischemia in intact hearts. Cardiovasc Res. 2004 Feb;61(3):580-90.

56 Dede S, Deger Y, Meral I. Effect of short-term hypothermia on lipid peroxidation and antioxidant enzyme activity in rats. J Vet Med A Physiol Pathol Clin Med. 2002 Aug;49(6):286-8.

57 Alva N, Palomeque J, Carbonell T. Oxidative stress and antioxidant activity in hypothermia and rewarming: can RONS modulate the beneficial effects of therapeutic hypothermia? Oxid Med Cell Longev. 2013;2013:957054.

58 Yaster M, Koehler RC, Traystman RJ. Interaction of fentanyl and nitrous oxide on peripheral and cerebral hemodynamics in newborn lambs. Anesthesiology. $1994 \mathrm{Feb} ; 80(2): 364-71$. 
59 Hägerdal M, Harp J, Nilsson L, Siesjö BK. The effect of induced hypothermia upon oxygen consumption in the rat brain. J Neurochem. 1975 Feb;24(2):311-6.

60 Auriat AM, Klahr AC, Silasi G, Maclellan CL, Penner M, Clark DL, et al. Prolonged hypothermia in rat: a safety study using brain-selective and systemic treatments. Ther Hypothermia Temp Manag. 2012 Mar;2(1):37-43.

61 Portera-Cailliau C, Price DL, Martin LJ. Nmethyl-D-aspartate receptor proteins NR2A and NR2B are differentially distributed in the developing rat central nervous system as revealed by subunit-specific antibodies. J Neurochem. 1996 Feb;66(2):692-700.
62 Martin LJ, Al-Abdulla NA, Brambrink AM, Kirsch JR, Sieber FE, Portera-Cailliau C. Neurodegeneration in excitotoxicity, global cerebral ischemia, and target deprivation: A perspective on the contributions of apoptosis and necrosis. Brain Res Bull. 1998 Jul;46(4):281-309.

63 Portera-Cailliau C, Price DL, Martin LJ. Excitotoxic neuronal death in the immature brain is an apoptosis-necrosis morphological continuum. J Comp Neurol. 1997 Feb;378(1):70-87.

64 Portera-Cailliau C, Price DL, Martin LJ. NonNMDA and NMDA receptor-mediated excitotoxic neuronal deaths in adult brain are morphologically distinct: further evidence for an apoptosis-necrosis continuum. J Comp Neurol. 1997 Feb;378(1):88-104.
65 Zhu C, Xu F, Wang X, Shibata M, Uchiyama $\mathrm{Y}$, Blomgren K, et al. Different apoptotic mechanisms are activated in male and female brains after neonatal hypoxia-ischaemia. J Neurochem. 2006 Feb;96(4):1016-27.

66 Hill CA, Alexander ML, McCullough LD, Fitch RH. Inhibition of X-linked inhibitor of apoptosis with embelin differentially affects male versus female behavioral outcome following neonatal hypoxia-ischemia in rats. Dev Neurosci. 2011;33(6):494-504. 